\title{
LA MUJER DEL DISCURSO JURÍDICO: UNA APORTACIÓN DESDE LA TEORÍA CRÍTICA DEL DERECHO ${ }^{1}$.
}

Juana María Gil Ruiz ${ }^{2}$

\section{Resumen}

Recuperar la obra de Carole Pateman La mujer del discurso jurídico permite reparar en las tres fases señaladas por ella en torno a la crítica feminista del Derecho. Conectar estos tres períodos -el Derecho es sexista, el Derecho es masculino y el Derecho tiene género- en un marco de análisis prioritario como es la violencia de género en el contexto de pareja, permite detectar que no sólo urge una reflexión y evaluación de la apuesta legislativa adoptada por el Estado español, sino también y muy especialmente, la revisión y falsación de categorías científico-jurídicas aprendidas y aprehendidas desde la Academia y aplicadas de manera automática en las resoluciones judiciales. Este anacronismo científico, sólo añade más violencia (victimización secundaria) a las mujeres que finalmente deciden denunciar. Finalmente, el blindaje del concepto de violencia de género, que vincula ciudadanas y Estado, se erige como fundamental ante el peligro inminente de disolución jurídica de éste en la violencia doméstica o familiar que nos regresa indefectible y peligrosamente a la víctima vulnerable.

Palabras Clave: Violencia de género, Ciudadanía, diligencia de Estado, ciencia jurídica

\section{INTRODUCCIÓN}

Hace ya casi 25 años, el 16 de mayo de 1991, una de las Feministas más reconocidas a nivel internacional, Carole Pateman presentó una conferencia con motivo de la toma de posesión de la cátedra de Belle van Zuylen, en la School of Women' Studies de la Universidad de Utrecht. Esa conferencia, titulada The Woman of Legal discourse (La mujer del discurso jurídico) ${ }^{3}$ fue posteriormente publicada en el volumen 1 (1992) de la prestigiosa revista Social and Legal Studies, erigiéndose en una de las aportaciones más significativas al mundo de la reflexión jurídico-política desde la Teoría crítica. En la misma identificaba tres períodos en la crítica feminista al Derecho; a saber: el Derecho es sexista, el Derecho es masculino, y por último, el Derecho tiene género.

\footnotetext{
${ }^{1}$ Este trabajo se enmarca dentro del Proyecto de Investigación I+D+i Orientado a los Retos de la Sociedad, DER2014-57244-R del Ministerio de Economía y Competitividad, titulado Carencias y alternativas jurídico-políticas al tratamiento de las Violencias de Género: Formación e Investigación en Derecho Antidiscriminatorio. Responsable principal: Juana María Gil Ruiz.

${ }^{2}$ Catedrática de Filosofía del Derecho. E-mal: jgil@ugr.es

${ }^{3}$ Puede consultarse en español en PATEMAN, C., "La mujer del discurso jurídico”, en LARRAURI PIJOÁN, E. (ed.), Mujeres, Derecho Penal y Criminología, Siglo XXI de España Editores, 1994. Traducción de Elisabeth Almeda.
} vol.08, n. 03, Rio de Janeiro, 2015.pp. 1441-1480 
Desde entonces hasta ahora, la Violencia de Género en el contexto de pareja y las víctimas que se cobra anualmente vienen ocupando un lugar central en el debate social y mediático, y han impulsado en lo que a España se refiere, una avalancha de reformas legislativas para intentar erradicar esta lacra de devastadoras consecuencias personales y sociales. De hecho, diez años se han cumplido ya de la aprobación de la rompedora y polémica L.O.1/2004, de 28 de diciembre de medidas de Protección Integral contra la Violencia de Género, sin duda, una de las apuestas más serias y rigurosas -yo diría a nivel internacional- para erradicar dicha lacra. Sin embargo las lagunas e insatisfacciones en torno a su implementación, siguen poniéndola en la palestra y en la picota del paquete de "leyes que requieren reformas".

No puede ser de otro modo, habida cuenta de las cifras arrojadas -se maneje la fuente que se maneje- de mujeres asesinadas a manos de sus parejas o exparejas en estos últimos años. Los datos son sin duda escalofriantes. Si ETA consiguió erigirse en 42 años (entre 1968 y 2010) en un notable puesto del escalafón de asesinatos ciudadanos en lo que al Terrorismo Político se refiere, con un total de 829 víctimas, el Terrorismo de Género no se queda atrás con 757 mujeres asesinadas, entre 2003 y el 25 de noviembre de 2014. Hablamos, pues, de más 700 asesinatos en 10 años de "celebración" de la entrada en vigor de la Ley de Medidas de Protección Integral contra la Violencia de Género de 2004; lo que resume una media anual en España de 70 asesinatos a mujeres por su pareja o expareja.

En el marco de esta violencia, nuevos elementos se suman y complejizan el problema. El porcentaje de mujeres adolescentes y jóvenes que padecen violencia de género se ha elevado a cotas significativas ${ }^{5}$. Seguramente, el "espejismo de la igualdad" generado por los recientes esfuerzos legislativos en pro de la igualdad efectiva y de la erradicación de las distintas formas de violencia de género haya supuesto, especialmente para la juventud, un falso oasis de emancipación de los seres humanos y una "bajada de guardia" en lo que a protección de la libertad, igualdad y seguridad se refiere.

De este modo, escribir sobre derechos y grupos vulnerables, reflexionar sobre la libertad, la igualdad y la seguridad, o sobre sus vacíos, exige más que nunca detenerse en la problemática de la Violencia de Género y en las

\footnotetext{
${ }^{4}$ Esta ley está siendo revisada, para su reforma, tanto en el Parlamento español, como en Comunidades autónomas tal que la andaluza (Ley 13/2007, de 16 de noviembre, de Medidas de Prevención y Protección Integral contra la Violencia de Género.

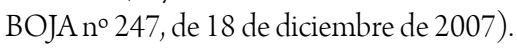

${ }^{5}$ ANAR, la fundación de Ayuda a Niños y Adolescentes en Riesgo, sostiene que la cifra de menores que sufren algún tipo e violencia de género en España ha crecido cerca del 35\% con respecto al 2014. Así se pronuncia Leticia Mata, directora de la Línea Telefónica de la Fundación ANAR: "Lamentablemente las llamadas al teléfono ANAR por violencia de género hacia menores han ido aumentando progresivamente desde el año 2009. Ese año recibimos 278 llamadas y durante el 2014 hemos tenido 1.920". Asimismo la fundación constata que el maltrato no es una cuestión de clases sociales, ni de credos ni de razas. Las encuestas especifican que el $45 \%$ de las jóvenes que lo denuncian conviven con ambos padres y que son mayoritariamente de origen español. Las edades con las que se identifican a los agresores van desde los 12 a los 30 años. Otro dato merece apuntarse por su gravedad: cerca del 50\% de las niñas y adolescentes que son víctimas de maltrato no registran este fenómeno como violencia per se. Esto puede deberse a lo difícil que resulta a esa edad identificar y percibir insultos, extorsiones y amenazas como una situación grave por la que no deben pasar". Vid. BECH, Laura, "Los adolescentes no perciben la violencia como tal", en Blasting News, Sociedad, 19 de mayo de 2015.
} 
ciudadanas -que no víctimas, en el sentido más pobre y devaluado de la palabra- que diariamente se cobra el terrorismo doméstico. La sensibilización social que sobre el tema existe, pese a todo, dista mucho de la empatía y de la angustia que otras formas de violencia, como el terrorismo político, genera en nuestra ciudadanía. Hoy en día, la última encuesta del CIS de 2014 sitúa la violencia de género en los últimos puestos de la lista de preocupaciones de la población española, por debajo de la "crisis de los valores".

Pero, en este texto no pretendo abordar, ni siquiera acercarme a todos los puntos débiles o gordianos que posee el tratamiento jurídico-político ${ }^{6}$ de los episodios de violencia de género en el contexto de pareja. Y las razones no sólo descansan en cuestiones de brevedad sino de inconmensurabilidad del problema que reatraviesa a más del 52\% de la ciudadanía mujeres a nivel mundial. La Organización Mundial de la Salud eleva a un tercio (1/3) de la población global la ratio de mujeres que padecen violencia de género. El 38\% de los asesinatos de mujeres en el mundo han sido por violencia de género. El 30\% de mujeres entre 15 y 19 años está sufriendo violencia de género por parte de su pareja o expareja. 7 de cada 10 mujeres en México ha sufrido esta violencia alguna vez en su vida, incrementándose los asesinatos en los últimos años. Sin duda, hablar de feminicidio internacional $l^{7}$ no podría calificarse de exagerado tras estos datos, sino todo lo contrario. Hablamos de violencia estructural hacia las mujeres con resultado de muerte, que exige respuestas institucionales inmediatas y urgentes.

Apenas introducida la problemática de la que parte mi aportación, debo centrarme en el nodo de la misma. No creo que el problema resida estrictamente que en la defectuosa configuración de la ley, aunque sin duda sea más que mejorable. La gravedad de esta victimización secundaria añadida a las mujeres y menores víctimas de la violencia de género, viene de la mano de la descoordinación ${ }^{8}$, de la ignorancia en la metodología de género $^{9}$ y de las especiales características de la violencia contra las mujeres ${ }^{10}$, de la falta de recursos económicos y humanos, de la falta de voluntad política, y como no, de una ciencia jurídica que sigue aplicando patrones y cánones no revisados ni falsados en el marco de la violencia de género.

\footnotetext{
${ }^{6} \mathrm{Al}$ respecto, pueden consultarse, entre otros, SCHNEIDER, E., "Mujeres maltratadas y la elaboración de leyes feministas: definición, identificación y desarrollo de estrategias”, en DI CORLETO, J., (Comp.), Justicia, género y violencia, Libraria, Buenos, Aires, 2010, pp. 23-42. SCHMAL, N., CAMPS, P., "Repensando la relación entre la ley y la violencia hacia las mujeres: una aproximación a los discursos de los/las agentes del ámbito judicial en relación a la ley integral de violencia de género en España”, en Psicoperspectiva. Individuo y Sociedad, vol. 7, n 1, 2008, pp. 33-58.

${ }^{7}$ Merece la pena la lectura de LAGARDE, M., "Sinergia por nuestros derechos humanos. Ante la violencia contra las mujeres en España, Guatemala y México", en LAGARDE, M. y VALCÁRCEL, A., (coord.), Feminismo, género e igualdad, Madrid, Agencia Española de la Cooperación Internacional para el desarrollo, Fundación Carolina, 2011, pp. 63-83.

${ }^{8}$ Puede consultarse entre otros trabajos, CÁRDENAS, M., CARCIA, L, "Límits i possibilitats de la coordinació informal els circuits locals contra la violencia de gènere", Comunicación al II Congreso Catalán de gestión pública, julio de 2006. Disponible en internet en el link: http://www20.gencat.cat/portal/site/eapc/memuitem.ca54cfbb17b4abf5272a63a7b0c0ela0.

${ }^{9}$ Apenas para aproximarse, véase FACIO, A, "Metodología para el análisis de género del fenómeno legal", en FACIO, A. y FRÍES, L. (coord.), Género y derecho, Santiago de Chile, LOM/La Morada, 1999, pp. 99-136.

${ }^{10}$ Algunos de estos aspectos pueden consultarse en CUBELLS, J., CALSAMIGLIA, A., ALBERTíN, P., "El ejercicio profesional en el abordaje de la violencia de género en el ámbito jurídico-penal: un análisis psicosocial”, en Anales de psicología, 2010, vol. 26, nºl, pp. 369-377.
} 
Si me permiten, éste será el objetivo de mi trabajo, y deseo centrarme en él, porque entiendo que más que una modificación legislativa, urge la revisión de su puesta en marcha por el poder judicial, apegado a las categorías dogmáticas de la doctrina científico jurídica. De nada sirve una ley justa -si es que esto fuera posible- si su aplicación e interpretación contradice el espíritu de la misma, de la mano además de una doctrina científica enseñada y transmitida desde nuestras aulas universitarias.

\section{UN REPASO POR EL DERECHO PENAL: DE LA FALTA AL DELITO}

Desde el año 1989, año en el que por primera vez se recoge el delito de malos tratos habituales en el antiguo Código Penal español, hasta nuestros días, esta lacra social ha sido "reformulada" jurídicamente hablando en numerosas ocasiones. La última respuesta legislativa ha sido la controvertida -pese a su aprobación unánime por todas las fuerzas políticas- Ley Orgánica de Medidas de Protección Integral contra la Violencia de Género de 28 de diciembre de 2004. Sin embargo, la visibilización de la violencia en el contexto familiar y su calificación como delito ha sido muy reciente (1989), constatándose el desinterés del legislador español por abordar episodios de violencia hacia los derechos humanos en el contexto familiar y aún más de pareja.

Bien es verdad que el antiguo Código Penal español contemplaba las lesiones con carácter general con independencia de los sujetos activos y pasivos, en los artículos 147 a 156 en caso de delito, y en el artículo 617 para el de falta. La determinación de uno u otro dependerá del resultado lesivo, esto es, de si se requiere para su curación más de una primera asistencia médica.

Sin embargo, la existencia de una serie de conductas violentas hacia la mujer era un hecho evidente. Una ojeada por el Código Penal nos revela que, aunque no haya en general distinción de sexo en ninguno de los tipos recogidos -a excepción de aquellos que sí pueden estar relacionadas con el sexo, como es el caso de suposición del parto, el delito de aborto-, existe una presencia -sociológica-mayoritaria de las mujeres como sujeto pasivo de determinados delitos. Entre ellos, merecen destacarse los referidos a agresiones sexuales o a violencias habituales sobre el que sea o haya sido cónyuge o sobre persona que esté o haya estado ligada a él de forma estable por análoga relación de afectividad. Por el contrario, no hemos encontrado ningún tipo penal cuya víctima sea el hombre como consecuencia del papel que ocupa en la sociedad.

Fue precisamente la alarma social surgida ante los cuantiosos episodios de agresiones dentro del hogar lo que motivó una reacción institucional a nivel internacional, nacional, autonómico y local. De hecho, y en lo que al ámbito internacional ${ }^{11}$ se refiere, desde la Convención para la eliminación de todas las formas de discriminación contra la mujer de 1979 hasta la revisión realizada en Nueva York en el 2000 de la Plataforma de Beijing de 1995,

\footnotetext{
${ }^{11}$ Para una información más completa al respecto, véase FREIXES SANJUÁN, T., "Las normas de prevención de la violencia de género. Reflexiones en torno al marco internacional y europeo”, Artículo 14. Una perspectiva de género, Instituto Andaluz de la Mujer, nº 6, 2001, pp. 4-20.
} 
la ONU ha emprendido importantes campañas de concienciación para erradicar el terrorismo doméstico. Las Conferencias mundiales sobre la mujer de México (1975), Copenhague (1980), Nairobi (1985) y Beijing (1995), la Declaración de la Asamblea General y la Conferencia mundial sobre los derechos humanos de 1993, la Resolución de la Asamblea General de 1998 respecto de la prevención de la violencia sobre las mujeres y el Protocolo facultativo a la Convención de 1979 adoptado por la Asamblea General en 1999 son un buen ejemplo de ello.

De hecho, en nuestro país, no será sino hasta 1984 cuando se hagan públicas por vez primera las cifras de denuncias por malos tratos en las comisarías de Policía ${ }^{12}$. Lo alarmante de la situación motivó una reacción institucional no sólo a nivel nacional, sino también autonómico y local. Dentro de la Comisión de Derechos Humanos en el Senado, se dedicará una Ponencia especial de investigación a la problemática de los malos tratos en España, y que pretende "con presupuestos concretos, (...) erradicar progresiva y definitivamente esta lacra social que es la violencia doméstica, y así paliar sus graves consecuencias tanto en el plano individual, como familiar y social" $^{\prime 13}$. Los resultados de esta Comisión no se hicieron esperar. La Ley Orgánica 3/1989, de 21 de junio, introducirá el artículo 425 en el Código Penal vigente a la sazón, tipificando por primera vez el delito de malos tratos vertidos en el seno de la unidad familiar. Posteriormente, el Código Penal de 1995 lo recogerá en su artículo 153 aunque su contenido sería también modificado por ley orgánica en 1999 y en el 2003. Actualmente, tras estas numerosas y atropelladas reformas ${ }^{14}$, el nuevo Código Penal lo recoge en su artículo 173.

Sin embargo, el Código Penal volvió a modificarse no sin haberse librado previamente una batalla discursiva durante su trámite parlamentario. La Ley Orgánica 1/2004, de 28 de diciembre, de medidas de protección integral contra la violencia de género modificó, entre otros preceptos, el artículo 153, dejando intacto el artículo 173, creando tipos penales específicos agravados y centrando especialmente su atención cuando la lesión se produzca contra quien sea o haya sido la esposa del autor, o mujer que esté o haya estado ligada a él por análoga relación de afectividad, aun sin convivencia.

\footnotetext{
${ }^{12}$ En 1984, fueron 16.070 las denuncias por malos tratos recogidas en las comisarías de policía. Según el propio Ministerio del Interior, cada año se presentan en nuestro país una media de 18.000 a 20.000 denuncias por malos tratos físicos y, o psíquicos a mujeres. Esta cifra representa menos del 10\% del total de los casos de malos tratos a mujeres que se producen anualmente en España. Según esta última consideración, se estima una cifra negra de 200.000 agresiones silenciadas.

${ }^{13}$ Véase el Informe de la Ponencia creada en el seno de la Comisión de relaciones con el Defensor del Pueblo y de los derechos humanos encargada del estudio de la problemática de la mujer maltratada, basado básicamente en datos estadísticos aportados por el Ministerio del Interior.

${ }^{14}$ Si originariamente el delito de "violencia doméstica" se ubicaba en el artículo $153 \mathrm{CP}$, aunque con reformas de su contenido por parte de la Ley Orgánica 14/1999 de 9 de junio (BOE no 13, de 10 de junio), cuatro años después, vuelve a modificarse el Código Penal mediante Ley Orgánica 11/2003, de 29 de septiembre, de medidas concretas en materia de seguridad ciudadana, violencia doméstica e integración social de los extranjeros, alterando el contenido de los artículos 153 y 173 que posteriormente pasaremos a tratar. La recién aprobada Ley Orgánica de Medidas de Protección Integral contra la Violencia de Género, de 28 de diciembre de 2004, ha vuelto a modificar el Código Penal agravando las penas, así como ha activado nuevas medidas en ámbitos que tienen que ver con la violencia de género tales como la prevención, protección, atención sanitaria, social y laboral, y por supuesto, la coordinación judicial.
} 
Todo este "correr" por el Derecho Penal ${ }^{15}$ constata, desde hace apenas unos años (1989), la abulia y el eterno desinterés del legislador español por abordar episodios de violencia hacia los derechos humanos en el contexto familiar (violencia doméstica) y muy especialmente hacia las mujeres como ciudadanas (violencia de género). Habrá que esperar, como sabemos, a la ya mencionada y conocida popularmente como Ley Integral para que se creen tipos específicos agravados y se considere delito (que no falta) la agresión que se produzca de hombre a mujer en el contexto de pareja y se abrace la violencia de género, bien es verdad que sin "denominar" en el Código Penal..

De cualquier modo, lo importante de este último paso legislativo no fue su agravamiento de las penas en el Código Penal -tampoco tan significativas-, sino el acuñar y amparar un nuevo concepto jurídico con un especial potencial transformador. Nos referimos al concepto de Violencia de Género, nada que ver con el hasta ahora calificado como Violencia doméstica o familiar.

La violencia de género no es un problema que afecte al ámbito privado. Al contrario, se manifiesta como el símbolo más brutal de la desigualdad existente en nuestra sociedad. Se trata de una violencia que se dirige sobre las mujeres por el hecho mismo de serlo, por ser consideradas por sus agresores, carentes de los derechos mínimos de libertad, respeto y capacidad de decisión ${ }^{16}$.

Se trata de "una manifestación de la discriminación, la situación de desigualdad y las relaciones de poder de los hombres sobres las mujeres"17. En definitiva, este concepto mira a los ojos de las mujeres como ciudadanas que no como colectivo, y zarandea al Estado en su deber de diligencia ${ }^{18}$, en tanto que garante del orden y la paz social. Esta es la razón por la que se establecen "medidas de protección integral cuya finalidad (sea) prevenir, sancionar, y erradicar esta violencia y prestar asistencia a sus víctimas" ${ }^{19}$.

Por el contrario, la violencia doméstica o familiar no deja de ocuparse de la agresión sufrida por una persona especialmente vulnerable en un entorno familiar (sea hombre o mujer). Aquí no hablamos de discriminación estructural que afecta a las ciudadanas, sino de agresión a un individuo que resulta víctima vulnerable en su relación familiar concreta.

Por lo tanto, el paso de la "simple protección jurídica de las víctimas de violencia doméstica o familiar" a la necesidad de combatir y erradicar la violencia de género como forma de discriminación estructural ciudadana significa romper con la idea de seres vulnerables, débiles, necesitados de protección, con el consiguiente

\footnotetext{
${ }^{15}$ Una de las aportaciones críticas más recientes y sugerentes la hallamos en BODELÓN, E., (Coord.), Violencia de Género y las respuestas de los sistemas penales, Ed. Didot, Buenos Aires, 2012. Asimismo, debe consultarse DI CORLETO, J., "La construcción legal de la violencia contra las mujeres”, en DI CORLETO, J., (comp.), Justicia, género y violencia, Libraria, Buenos Aires, 2010, pp. 9-22.

${ }^{16}$ Exposición de motivos de la L.O.1/2004, de 28 de diciembre, de Medidas de Protección Integral contra la Violencia de Género.

${ }^{17}$ Art. 1 de la L.O. 1/2004, de 28 de diciembre, de Medidas de Protección Integral contra la Violencia de Género,

${ }^{18}$ Véase la nota editorial de GIL RUIZ, J.M., (ed.) así como el monográfico del no 48 de la revista Anales de la Cátedra Francisco Suárez, dedicado a la Violencia Institucional de Género, Granada, 2013, pp.9-158.

${ }^{19}$ Ibidem
} 
tratamiento paternalista de amparo, y reemplazarla por el reconocimiento de la ciudadanía de las mujeres, visibilizando -en caso de desprotección- la incapacidad del Estado de garantizar a éstas el pleno ejercicio de los derechos fundamentales a la vida, integridad, igualdad, libertad y seguridad.

Sin embargo, siguiendo con el hilo de nuestra argumentación anterior, y pese a los incuestionables avances legislativos -aun cuando mejorables ${ }^{20}$ - referentes a la consecución de la igualdad efectiva de la ciudadanía y erradicación de las distintas formas de violencia de género, nuestras Facultades de Derecho siguen extrapolando un modelo de ciencia jurídica, desfasado, propio del siglo XIX, inmune a cualquier crítica, en tanto que convertido en dogma científico, una suerte de Teología jurídica, no revisable ni falsable. La reticencia a reconocer la alevosía, la adoración al principio de presunción de inocencia frente al cuestionamiento de los especiales conocimientos de la víctima, la "habitualidad" de la agresión como requisito matemático exponencial, y la invención doctrinal de un animus subjetivo de dominación por parte del agresor son, entre otros, ejemplos de categorías elevadas a dogmas, símbolo de cómo el Derecho, este nuevo Derecho, se estrella ante el pseudo-arrecife de la neutralidad interpretativa.

Pese a las distintas reformas penales, algunas de las exigencias típicas de estos preceptos siguen planteando importantes dudas interpretativas que requieren de una reflexión crítica, al menos desde la Filosofía del Derecho. Si es cierto que la reivindicación primigenia de arribar a la igualdad ha supuesto la reformulación y la promulgación de leyes expresadas de forma neutral respecto del género, sin embargo, esta política de exigir un trato igual provoca ciertas dudas, ya sugeridas por la Feminist Jurisprudence. Decir que a la mujer se le tratará como al hombre no supone evidentemente que se le trate igual; acogerse a la neutralidad de la ley eclipsa la auténtica interpretación masculina que rige en ella.

De este modo, el Derecho se percibe como algo construido histórica y concretamente sobre las experiencias, las opiniones y los intereses de los varones. No es masculino por estructura o vocación, sino por elaboración histórica de varones para varones, lo que no significa que las mujeres no aparezcan. Como nos recuerda Pitch "el Derecho se concibe de dos modos, según un modelo masculino y uno femenino, este último originado por las percepciones masculinas acerca de cómo son las mujeres o de cómo deberían ser"21.

\footnotetext{
${ }^{20} \mathrm{Al}$ respecto, véase AÑÓN, M.J, “¿Igualdad ma non troppo? Una reflexión crítica sobre la reciente legislación española en materia de igualdad entre mujeres y hombres”, en Sociología del Diritto, Franco Angeli Edizioni, vol. 34, Italia, 2008. Asimismo, deben consultarse AÑÓN, M.J. y MESTRE i MESTRE, R., "Violencia contra las mujeres: discriminación, subordinación y Derecho", en BOIX, J. y MARTÍNEZ, E. (coord.), La nueva Ley contra la Violencia de género, Madrid, Iustel, 2005, pp. 31 -63. CGPJ, Informe del Grupo de Experto/as en violencia de género y doméstica del CGPJ acerca de los problemas técnicos detectados en la aplicación de la L.O.1/2004, CGPJ, Madrid, 2011; HEIM, D., "Acceso a la Justicia y violencia de género", Anales de la Cátedra Francisco Suárez, nº 48, Granada, 2014, pp. 107-130.

${ }^{21}$ Vid. PITCH, T., Un Derecho para dos. La construcción jurídica de género, sexo y sexualidad, Editorial Trotta, Madrid, 2003, p. 262.
} 
La Feminist Jurisprudence propone dos opciones para combatir la desigualdad estructural que desembocan en la reivindicación de la diferencia, combatiendo la falsa idea de igualdad, y la subordinación asociada a la diferencia. Pero, retomemos a MacKinnon:

Hay dos opciones. La primera la llamo el standard masculino: Las mujeres pueden ser iguales a los hombres. En derecho se llama neutralidad. La otra opción la llamo el standard femenino: Puedes ser diferente de los hombres. En derecho se llama protección especial. De cualquiera de las formas son los hombres los que articulan el standard bajo el cual se mide. Puedes ser lo mismo que un hombre, y entonces serás igual, o puedes ser distinta de los hombres, y entonces será mujer ${ }^{22}$.

Toda esta reflexión nos obliga a reparar en los tres períodos señalados por Carol Smart en La mujer del discurso jurídico, en torno a la crítica feminista al Derecho. El primero de ellos se sitúa en la afirmación de que "el Derecho es sexista"; el segundo con la frase "el Derecho es masculino", y finalmente, en un tercer estadío se argumenta que el "Derecho tiene género". Si el primero de ellos obligaba a revisar todos los preceptos de Derecho Penal bajo la lupa del principio de igualdad de trato, plasmándose de factum no sólo en exigencias de criminalización, sino también en demandas de despenalización; el segundo -el Derecho es masculino- aludía a la constatación de que estas leyes formuladas de forma neutral, sin embargo, se aplican de acuerdo a una perspectiva masculina y toman como medida de referencia a los hombres.

Por esta razón, -continúa Smart- comparado con el enfoque anterior, "el Derecho es sexista", este análisis sugiere que cuando un hombre y una mujer están frente al derecho, no es el derecho el que fracasa en aplicar al sujeto femenino los criterios objetivos, sino que precisamente aplica criterios objetivos y éstos son masculinos. Por ello, insistir en la igualdad, la neutralidad y la objetividad resulta, irónicamente, insistir en ser juzgado bajo valores masculinos ${ }^{23}$.

Sin embargo, no pensemos que esta parcialidad real del Derecho -que no formal- se debe a una aplicación errónea de la ley en lo que al juez e intérprete se refiere; esto es, al supuesto talante machista de éste. Lo que pretendemos demostrar va aún más lejos: la aplicación objetiva del Derecho tiende a reproducir la versión social dominante; y esto es así, aplique el Derecho un hombre o una mujer ${ }^{24}$. La aplicación dogmática de la ley, y el cumplimiento estricto de todos los requisitos admitidos por la Doctrina, puede llevar a una desprotección legal y real de determinados colectivos, y todo ello - y paradójicamente- por mor del supuesto principio igualitario.

22 Palabras de MacKinnon citadas por EISENSTEIN, A., The female body and the law, Berkeley, University of California Press, 1988. En este sentido, véase LAURENZO, P., "La violencia de género en el Derecho Penal: un paternalismo punitivo", en LAURENZO, P, MAQUEDA, M.L., RUBIO, A. (ed), Género, violencia y Derecho, Tirant lo Blanch, Valencia, 2008, pp. 329-362. 23 SMART, C., "La mujer del discurso jurídico", opus cit., p. 173.

$24 \mathrm{Al}$ respecto, tengamos en cuenta la polémica sentencia de la Audiencia Provincial de Barcelona, de 31 de enero de 1997, siendo ponente del Tribunal, la Ilma. Sra. Magistrada Da Ana Ingelmo Fernández, y en la que se estima que una violación practicada dentro del matrimonio genera menos ansiedad, temor y daño psicológico que la agresión sexual perpetrada por un extraño, que no marido. Obsérvese cómo el "débito conyugal", parece seguir arraigado en el interior del inconsciente colectivo. 
Pero, a diferencia de estas dos etapas en la crítica feminista al Derecho, las aportaciones que revisan la idea de que el "Derecho tiene género" nos ha llevado a preguntarnos más que el modo con que el Derecho supera el género, cómo funciona el género dentro del Derecho y cómo el Derecho funciona para crear género.

Además, el Derecho es redefinido no como el sistema que puede imponer la neutralidad del género, sino que se define como uno de los sistemas (discursos) que produce no solamente las diferencias de género sino formas específicas de diferencias polarizadas. El Derecho se ve como creando ambos sujetos con género y también (más discutible) subjetividades o identidades a las cuales el individuo deviene atado o asociado ${ }^{25}$.

Quizás, todo este triple proceso, que sin duda puede calificarse de complejo, pueda verse con mayor nitidez en el ámbito de la domesticidad, ámbito invisible, privado e íntimo, que ha venido manteniendo su propia legislación despótica, y su jurisdicción extra-jurídica. Constatamos con facilidad la primera de las etapas señaladas, "el derecho es sexista", y la consecuente reacción de despenalización y criminalización de conductas. La abolición del delito de adulterio y la incorporación del delito de malos tratos da buena cuenta de ello. A continuación, detectaremos la segunda de las etapas reseñadas, "el derecho es masculino". La reticencia a observar la agravante de alevosía en los casos de muerte de la víctima, o el conflicto tradicional entre los conocimientos especiales de la víctima y la presunción de inocencia mostrará la parcialidad de un Derecho que se presenta como universal. Por último, el análisis de criterios como el de "habitualidad" exigido por el legislador penal, tanto en su Proyecto de Ley Orgánica de Código Penal de 1992, como en su redacción actual, así como la exigencia de constancia comprobada de animus de dominación del agresor por parte de una incipiente línea jurisprudencial nos permitirá descubrir la tercera fase, que el "derecho tiene género", un género que se perpetúa a través de categorías dogmáticas. Ídem se ha detectado ${ }^{26}$ al observar la tendencia a aplicar atenuantes y eximentes completas e incompletas que justifican de algún modo la violencia, tales como la celotipia, la embriaguez, el trastorno mental transitorio o el desamor o por el contrario, el recelo en reconocer la eximente de legítima defensa en caso de que la agredida se defienda o la tendencia a aplicarle, en su caso, una atenuante por trastorno mental transitorio.

En este sentido, nuestro análisis se centrará en estas dos últimas fases e intentará mostrar el talante masculino de la Ciencia jurídica, y cómo funciona el género dentro del Derecho, incluso generándolo. La reacción bidireccional de la Ciencia jurídica ante el agresor, por un lado, y ante la agredida, -en caso de que ésta se defienda-, dando muerte a su maltratador, también es una buena prueba -aun cuando no podamos desarrollarlo ${ }^{27}$ - de cómo "el Derecho tiene género", un Derecho que se perpetúa a través de categorías dogmáticas. No en vano, apenas hemos detectado cambios en la aplicación de estas categorías, que de manera automática se ejecutan, sin revisión

\footnotetext{
25 SMART, C., "La mujer del discurso jurídico", opus cit., p. 177.

${ }^{26}$ Al respecto, véase GIL RUIZ, J.M., Los diferentes rostros de la Violencia de Género, Dykinson, Madrid, 2007. El desarrollo de esta investigación será próximamente publicado.

${ }^{27}$ No obstante, podrá encontrarse cumplida información en la obra anteriormente citada: GIL RUIZ, J.M., Los diferentes rostros de la Violencia de Género, opus cit.
} 
ni falsación en contextos de violencia contra las mujeres, pese a la vigencia de la unánimemente aprobada L.O.1/2004, de 28 de diciembre de Medidas de Protección Integral contra la Violencia de Género.

Entendemos por último, tal y como ha sido señalado por colectivos expertos ${ }^{28}$, que lo único que cambiaría la respuesta del Derecho a la violencia de género, por encima de modificaciones legislativas, es un verdadero cambio de actitud de los operadores jurídicos, -apartándose de la idea de encontrarse ante un problema privado y cuya resolución sólo incumbe a los propios afectados, y considerándolo en cambio como un problema público de devastadoras consecuencias sociales- que exige, para su erradicación, el compromiso, la formación y la consecuente incorporación de la perspectiva de género ${ }^{29}$ en la práctica judicial y en la ciencia jurídica en particular.

\section{EL DERECHO ES MASCULINO Y SINGULAR.}

\section{La agravante de alevosía en supuestos de violencia de género}

La alevosía se define como la actitud traicionera o cobarde por parte del agresor, quien ataca a la víctima bien utilizando medios, modos o formas para asegurar el resultado de lesionar o matar, o bien elimina una posible defensa por parte de la víctima. En este sentido, la doctrina jurisprudencial ha distinguido tres modalidades de alevosía: la proditoria ${ }^{30}$, que incluye a la traición; la súbita o inopinad ${ }^{31}$; y por último, otras formas consistentes en el aprovechamiento de una especial situación de desvalimiento ${ }^{32}$. Los criterios utilizados por los Tribunales para apreciar esta agravante no resultan ser uniformes, ${ }^{33}$ pero lo realmente preocupante reside en la importante

\footnotetext{
${ }^{28}$ Dentro de estas voces destacadas dentro de la Academia deben señalarse las posiciones de Maggy Barrère, Ana Rubio, María José Añón, Arantza Campos, Encarna Bodelón, o Juana María Gil. En el marco asociativo profesional, véase como ejemplo iniciario, ASOCIACIÓN DE MUJERES JURISTAS THEMIS, Respuesta penal a la violencia familiar, Consejo de la Mujer de la Comunidad de Madrid, 1999, p. 96.

${ }^{29}$ El Informe de Amnistía Internacional de noviembre de 2012 pone el acento en la falta de cumplimiento del deber de formación en género de la judicatura, abogacía -en especial, de la asistencia letrada gratuíta- y la fiscalía, añadiendo la propia predisposición de los operadores del Derecho que con prejuicios morales, infunden sospechas relacionadas con la falsedad de la denuncia e incluso, en los casos de mujeres extranjeras en situación irregular, la probable instrumentalización de la denuncia para obtener la autorización de residencia.

${ }^{30}$ Sentencia del TS de 22 de diciembre de 1992, RJ 1992/10465.

${ }^{31}$ Véanse las Sentencias del TS de 22 de febrero de 1991, RJ 1991/1349; de 14 de junio de 1991, RJ 1991/4718; de 18 de octubre de 1991, RJ 1991/7311; de 20 de abril de 1992, RJ 1992/3165; de 8 de marzo de 1993, RJ 1993/1992; y la de 9 de marzo de 1993, RJ 1993/2163, entre otras.

${ }^{32}$ Véanse las Sentencias del TS de 28 de mayo de 1992, RJ 1992/4396; de 4 de junio de 1992, RJ 1992/5444; la de 7 de mayo de 1993, RJ 1993/3860; y la de 3 de octubre de 1994, RJ 1994/7604, entre otras.

${ }^{33} \mathrm{La}$ STTS de 9 de octubre de 2000 es un buen ejemplo jurisprudencial donde se aprecia la agravante de alevosía. Dice así su FJ 2。 "Y de las modalidades instrumentales expresadas, es bien patente la presencia de la alevosía sorpresiva y también de la correspondiente al desvalimiento, ya que el hecho de clavar el cuchillo por la espalda, mientras la víctima se encuentra desp revenida, es incuestionablemente objeto de tal calificación jurídica que, en el caso, cualifica los hechos de asesinato". Con respecto a la jurisprudencia menor, destaquemos la Sentencia del Juzgado de lo Penal no 1 de Algeciras (Cádiz), siendo ponente el Sr. Pérez Pérez, en que se condena al agresor a un delito de lesiones con la agravante de alevosía -agresión cometida con un cuchillo de cocina y por la espalda- por entender: "En suma, teniendo en cuenta estos criterios, resulta incardinable la acción del acusado en la agravante de alevosía, en la segunda de las modalidades analizadas por la STS. de 24-1-92, la súbita o inopinada, al haberse vol.08, no.03, Rio de Janeiro, 2015.pp. 1441-1480 1450
} 
tendencia de los Tribunales a no apreciar la alevosía en caso de existencia de malos tratos anteriores por entender que la agredida quizás esté indefensa pero no desprevenida. Como muy bien señala Larrauri "la parcialidad de la formulación respecto del género puede verse adicionalmente en el hecho de que se considera que la mujer quizás sí está indefensa pero no a consecuencia de estar desprevenida (pues ha sido víctima de repentinos ataques), con lo cual su muerte no puede ser calificada de Heimtücke"34, esto es de muerte con la agravante de alevosía.

Un ejemplo de lo anteriormente afirmado lo hallamos en la STTS de 25 de julio de 2000 donde el Alto Tribunal estima parcialmente el recurso planteado por el acusado y le condena como autor de un delito de homicidio -que no de asesinato- con las agravantes de parentesco y abuso de superioridad, por entender que no hay elementos suficientes para apreciar la concurrencia de la agravante de alevosía. Los argumentos esgrimidos, varios: defectos procedimentales ${ }^{35} \mathrm{y}$ evidencia de no encontrarnos "ante una persona absolutamente desprevenida y que no pudiera percatarse o vislumbrar las intenciones agresivas del que hasta entonces era su esposo". Merece la pena la transcripción de parte de la sentencia citada:

Se dice, como antecedentes del desenlace mortal, que el acusado había tenido previamente varias discusiones violentas con su esposa, maltratándola incluso en pena calle. Es cierto que el día de los hechos esperó a que su esposa quedase sola en casa de sus padres, pero también se dice, a continuación, que consiguió que le abriese nuevamente la puerta iniciándose una previa y breve discusión. Este suceso debió advertir a la víctima sobre las intenciones agresivas de su irascible marido. A continuación se nos dice, de forma inconexa que sorprendió a la víctima, para afirmar después que le empujó por el pasillo hasta caerse ambos, continuando hasta el cuarto de baño a donde la siguió asestándole varias puñaladas en espalda, cara y ambas extremidades.

El relato fáctico, es como ya se ha dicho impreciso e incluso contradictorio, por lo que no encontramos base para apreciar una agresión súbita o traicionera.

Es evidente que no nos encontramos ante una persona absolutamente desprevenida y que no pudiera percatarse o vislumbrar las intenciones agresivas del que hasta entonces era su esposo. Existen antecedentes fácticos que nos demuestran que el comportamiento violento era casi una constante en los últimos encuentros. Si

efectuado el ataque por sorpresa y por la espalda, evitando así toda posible defensa de la agredida. Ello determina la aplicación de la agravante y de la consiguiente regla penológica del art. 66.3 del Código".

${ }^{34}$ LARRAURI, E., "Violencia doméstica y legítima defensa -un caso de aplicación masculina del Derecho-, en LARRAURI, E. y VARONA, D., Violencia doméstica y legítima defensa, E.U.B., Barcelona, 1995, p. 17. De cualquier modo, no entendemos por qué no se condenó al agresor a un delito de asesinato frustrado. Asimismo, otras aportaciones de la autora merecen destacarse: "Desigualdades sonoras, silenciosas y olvidadas: género y derecho penal", Anuario de la Facultad de Derecho de la UAM, Madrid, 2009, o "Violencia de género en España: Tres años después de la L.O. 1/2004, de 28 de diciembre de Medidas de Protección Integral contra la Violencia de Género”, en BIRGIN, H. \& GHERARDI, N., (coords.), Reflexiones Jurídicas desde la Perspectiva de Género, Editorial Fontamara, México D.F., 2011.

${ }^{35}$ El TS, en esta ocasión, se acoge a argumentos excesivamente formalistas y procedimentalistas -errores e imprecisiones en el acta del jurado; no estimación del Juez instructor de la devolución de este acta al jurado para su corrección...- creando -entiendo- una enorme situación de indefensión, impotencia e injusticia alrededor de la figura de la víctima (ver STTS de 25 de julio de 2000, FD 20. 1. 2. 3. y 4.). En este sentido, y por entender que existen contradicciones entre los hechos probados, el veredicto y la fundamentación del fallo, se rebaja el delito de asesinato al de homicidio. 
nos atenemos a los esquemas clásicos que configuran la alevosía por la concurrencia de la traición, el aseguramiento o la cobardía, tenemos que llegar a la conclusión de que, en los supuestos fácticos que nos relata la sentencia recurrida no están nítidamente perfilados ninguno de estos elementos componentes"36.

Asimismo se puede apreciar el modo en que actúa el "curriculum vitae de agresiones" o historial de malos tratos del acusado beneficiando al recurrente y perjudicando a la víctima. De este modo, el argumento del TS continúa: "Tampoco es posible construirla, sobre la base de la existencia de una relación de confianza entre agresor y víctima de tal manera que ésta no hubiera podido intuir un comportamiento agresivo de su marido, ya que, como se ha dicho, concurren circunstancias suficientes para descartar esta posibilidad, al constar que últimamente el acusado observaba una actitud agresiva cada vez que se encontraba con su esposa" ${ }^{37}$.

Ídem sucede en la Jurisprudencia menor. La Audiencia Provincial de Badajoz (Sección 1a) en Sentencia no 47/2011, de 21 de noviembre (ARP 2011/1371) afirma dicha tesis, al unísono -sorprendentemente- con lo también defendido por el Ministerio Fiscal que:

La Sala encuentra serias dificultades para apreciar en el presente caso tal circunstancia cualificatoria del asesinato, pues la víctima estaba ya prevenida sobre un posible ataque por parte de su pareja, ya que según ella misma ha reconocido, vio el cuchillo debajo de la cama, el mango del mismo, oculta la hoja con una camisa, por lo que la acción del sujeto pasivo no fue del todo sorpresiva, ni se eliminó totalmente la posibilidad de defensa de la víctima. En este sentido se posiciona el Ministerio Fiscal, cuya tesis se comparte por el Tribunal. Es decir, el ataque, por muy virulento que haya sido, no puede calificarse como alevoso por cuanto el sujeto pasivo no estaba inadvertido del peligro, pues al descubrir el cuchillo debajo de la cama pudo prever racionalmente un posible ataque de su pareja, al que previamente había visto "raro", le había dado un beso "frío" (según se expresó la víctima en el acto del juicio). Por tanto, el ataque pudo ser inopinado pero no imprevisto. Paralelamente a ello, el procesado no realizó ningún acto tendente a eliminar la defensa de la víctima o el aseguramiento del hecho. Simplemente acometió de forma violenta y desordenada, pero ello no caracteriza el ataque aleve.

Como podemos observar, la tónica jurisprudencial no ha cambiado en absoluto tras la aprobación y puesta en marcha de la Ley Integral de 2004, pese a que forma parte del moderno Derecho Antidiscriminatorio ${ }^{38}$. No en vano, no hallamos diferencias con pronunciamientos judiciales de hace treinta años. Un ejemplo de este continuum jurisprudencial, es la Sentencia de la Audiencia Provincial de Madrid de 21 de octubre de 1992 que no aplica la agravante de alevosía pese a que el agresor mata a su esposa golpeándola por la espalda con un martillo de forma sorpresiva mientras ve la televisión. Merece la pena leer parte de la enrevesada argumentación del Tribunal que llegó incluso a ir en contra de lo declarado por el imputado en su primera declaración:

\footnotetext{
${ }^{36}$ Sentencia del TS de 25 de julio de 2000, siendo Magistrado Ponente, el Ilmo. Sr. Martín Pallín. Fundamentos Jurídicos no 5 y 6.

${ }^{37}$ Ibidem, Fundamento Jurídico n $^{\circ} 6$.

${ }^{38} \mathrm{Al}$ respecto, véase GIL RUIZ, J.M., Las nuevas Técnicas Legislativas en España, Tirant Lo Blanch, Valencia, 2012. vol.08, nº. 03, Rio de Janeiro, 2015.pp. 1441-1480 
No concurre esta circunstancia porque, si bien la ausencia de signos de defensa en el cuerpo de la víctima, y de desorden en la habitación, unidos a lo señalado por el propio procesado en su declaración ante el juzgado, donde dice, "Ella estaba viendo la televisión y no le vio cuando él entraba en el salón, no se pudo defender...", podrían hacer pensar que el ataque que se produjo de forma súbita por la espalda, un estudio pormenorizado de los distintos datos que existen, llevan cuando menos a la duda sobre que la agresión se produjera en la forma anteriormente descrita, porque la ausencia de signos de defensa no bastan por sí solos para justificar esta circunstancia y la manifestación del imputado constituye una apreciación subjetiva y personal, que en modo alguno puede ser aceptada, al corresponder exclusivamente a los órganos judiciales esta valoración en atención a las circunstancias de cada caso, y en especial en el presente, por la situación que ocupaba la víctima al ser agredida, que era la de sentada en el borde del ángulo que formaba el sofá, compuesto por diversas piezas y colocado en forma de L, según se desprende sin ningún género de duda del lugar donde quedaron manchas de sangre, y no en el extremo más próximo a la puerta por la que accede su marido, con las piernas extendidas sobre la sección más corta del sofá, posición en la que se hallaba cuando sus hijos se marcharon del domicilio, y viendo la televisión, que estaba emplazada en el centro del mueble ubicado enfrente de la sección más larga del sofá, es decir, que miraba al frente con una ligerísima inclinación al lado izquierdo, como se deduce de las fotografías de la habitación (folios 31 y siguientes), con lo que su ángulo de visión hacia la derecha, dado al que se encontraba la puerta era bastante amplio, quedando en el mejor de los casos una pequeñísima zona muerta, desde la cual difícilmente podría ser golpeada por el acusado, quien casi tendría que haberse echado sobre el sofá para alcanzarla o cuando menos, apoyarse en él inclinándose sobre el mismo, lo que hubiera provocado el desplazamiento del módulo, que se hallaba perfectamente colocado cuando A. encontró a su madre, por lo que es más lógico pensar que bien el ataque se produjo de frente, como indica el procesado en el juicio, o al menos desde la derecha, y no por detrás, lo que permitía la posibilidad de defensa de la víctima, la cual no se encontraba mermada por la ingesta previa de bebidas alcohólicas, como se desprende del hallazgo de 1.5 gramos de alcohol por cada $1.000 \mathrm{~cm} 3$, de sangre, análisis efectuado por el Instituto Nacional de Toxicología (folio 97), según indican los peritos médicos en el acto del juicio, máxime si se tiene en cuenta la inmediatez de la agresión con la fuerte discusión verbal precedente, y que en casos anteriores había degenerado en agresiones físicas.

En esta misma línea, sin atisbo de modificación alguna, se pronuncia la Sentencia no 590/2005, del 10 de junio, de la Audiencia Provincial de Girona, ARP 2006/56, -tras la Ley Integral- donde el Tribunal realiza una prognosis de lo que, según entiende, podría haber pasado en el acontecimiento del ilícito, lo que le lleva incluso a interpretar en sentido negativo las pruebas periciales vertidas en el juicio, desdiciendo incluso lo testificado por el agresor.

El día 4-5-03, sobre las 23 horas y 30 minutos, en el domicilio sito en la calle (... ) , el acusado Miguel Ángel con la intención de causar la muerte a Eva, le asestó diversas puñaladas en varias zonas de su cuerpo con un cuchillo, lo que efectivamente produjo la muerte de ésta (...). Para conseguir su propósito el acusado Miguel Ángel se aprovechó deliberadamente de la ventaja que le proporcionaba tener en su poder un cuchillo, debilitando así 
las posibilidades de defensa de Eva. ( ... Efectivamente, el hecho principal objeto de la acusación en este procedimiento, la muerte de una persona a manos de otra, no ha presentado especiales dificultades probatorias dado que ha sido el propio acusado quien, con importantes matices relativos a las circunstancias concretas del hecho, ha reconocido tanto la causación de la muerte de Eva como su participación en el hecho. Por un lado, la etiología violenta de la muerte es evidente, La fallecida presentaba numerosas cuchilladas profundas en diversas partes de su cuerpo, siendo las principales las propinadas en el tórax y en el abdomen, de suerte tal una de ellas llegó a traspasar un sector pulmonar insertándose en el corazón y otra penetró por la zona mamaria izquierda insertándose hasta por dos veces también en el corazón. ( ...

Sin embargo, no podemos detenernos aquí dado que la calificación más grave de las acusaciones pretendía que el hecho no era constitutivo de un simple homicidio sino que entendían que se trataba de un delito de asesinato al concurrir la alevosía, circunstancia agravante genérica que en este concreto caso transforma el delito de homicidio en delito de asesinato. El Tribunal del Jurado ha considerado que tal alevosía, que las partes fundamentaban en la existencia de un ataque repentino e inesperado, ejercido con gran violencia, con la fallecida tumbada en la cama, no ha quedado acreditada. En efecto, los hechos acaecidos no han podido ser revisados en su configuración esencial sino a través de la declaración del acusado, dado que, por un lado no existían testigos presenciales de los hechos y, por otro, no se identificaban datos objetivos de gran relevancia que apoyasen las tesis acusadoras. ( ....) Así las cosas, en el presente supuesto, no queda en absoluto acreditado que el ataque homicida se produjera mientras la fallecida se encontraba descansando en la cama desprevenida, pues dicha tesis parte del hecho de que grandes manchas de sangre fueron halladas en el colchón que el acusado intentó hacer desaparecer, pues tales signos, no indican sino que en aquel lugar hubo un importante desprendimiento de sangre, pero el mismo pudo ser perfectamente posterior al inicio del ataque, es decir, por ejemplo, porque Eva, tras las puñaladas, cayera allí desvanecida o muerta ya. De igual manera tampoco se deduce la situación en la cama porque existan gotas de sangre en ambos lados de la cama, pues tales salpicaduras pudieron perfectamente producirse al sacar con violencia, manchado y goteando, el cuchillo que introdujo en varias ocasiones. Otro dato trascendental es la presencia en los manos y brazo de la fallecida de signos de defensa, es decir, que trató de interponer esas partes de su cuerpo en la trayectoria del cuchillo, lo que implica la existencia de una cierta prevención, que, fatalmente, no pudo evitar su muerte. En definitiva, así como el Tribunal del Jurado ha considerado que la declaración del acusado no es completamente veraz, pues muchas de sus afirmaciones y de sus olvidos no obedecen sino a deseos exculpatorios, de ese silencio no puede deducirse necesariamente la tesis contraria por las acusaciones.

La conclusión de dichas argumentaciones, como veremos, implica hacer recaer sobre la propia víctima la

obligación de permanecer alerta en todo momento para evitar cualquier resultado luctuoso y además, responsabilizarla de su acaecimiento. Sorprende el resto de la argumentación judicial en torno a:

Las dos hipótesis igual de lógicas -al decir del Tribunal- posibles y probables, pero con resultados opuestos en cuanto a la aplicación de la circunstancia agravante de alevosía. (... En el primero de los supuestos, más probable que el segundo, pues resulta más lógico que cuando se 
produce las heridas contusas en la cabeza y cara, el acusado todavía no tuviera el cuchillo, pues de lo contrario, ya lo habría utilizado, acuchillando a la víctima y no golpeándola en la cabeza, aparece con claridad que no hubo ninguna de las modalidades de alevosía, pues ni hubo traición, ni ataque súbito e inesperado, ni desvalimiento de la víctima, pues en relación a las agresiones que le producen las heridas en la cabeza no se produce de forma súbita e inesperada, ni a traición, sino con enfrentamiento entre víctima y agresor, aunque existiera superioridad física del agresor. Y, por lo que se refiere a los actos agresivos con el cuchillo, al haber transcurrido un tiempo, muy probablemente escaso, entre el momento en que se producen los golpes en la cabeza, estando en el pasillo, y cuando el agresor regresa de la cocina con el cuchillo, la víctima tuvo un margen de tiempo para refugiarse en el cuarto de baño o en el dormitorio o, incluso, para huir hacia la puerta de acceso a la vivienda, pero también proveerse de algún objeto para defenderse en caso de que el agresor regresara (...).

La decisión última del Tribunal hacia esta segunda opción no requiere mayor comentario. Baste su lectura para entender que la ciencia jurídica, sin revisión ni contraste con la perspectiva de género, ejerce un plus de violencia en las mujeres agredidas, demandado en éstas comportamientos heroicos sin precedentes. Concluye el Tribunal:

En definitiva, con esta hipótesis, que consideramos la más probable de acuerdo con el informe de los médicos forenses, ni se eliminó totalmente la defensa de la víctima, ni hubo aprovechamiento de la situación de indefensión, pues tuvo la posibilidad de defenderse, bien refugiándose tras la puerta de alguna de las habitaciones, bien escapando hacia la puerta de salida de la vivienda, y también cuando ya no podía escapar, se defendió con las manos intentando apartar el cuchillo cuando el acusado le lanzaba las cuchilladas y llegando a agarrar con la mano la hoja del cuchillo. (Audiencia Provincial de Zamora (Sección 1a), no 1/2010, de 15 de abril. ARP. 2010/636)

La alarma de esta violencia procedimental infligida a través de la aplicación automática -sin revisión de género- de la categoría de la alevosía, en procesos de violencia de género en el contexto de pareja, ha obligado a la recomendación de su falsación -en tanto que categoría científica que no dogma- incluso por el cuerpo de Fiscales en su ánimo por mejorar el seguimiento procedimental de esta lacra social. De este modo, en las Conclusiones del VIII Seminario de Fiscales Delegados en Violencia sobre la Mujer celebrado en Madrid durante el mes de octubre de 2012, determina textualmente en la número 7:

En los delitos contra la vida entre los miembros de la pareja o parientes, una discusión previa entre agresor y agredido no impide la apreciación de la circunstancia agravante de alevosía pues, precisamente, la convivencia, generadora de una cierta sensación de confianza y seguridad, hace que la víctima no espere ni imagine un ataque de tal gravedad y naturaleza, lo que implica que aquella no pueda poner en marcha ningún mecanismo de defensa, ni suponer ningún riesgo para su agressor.

Esta percepción es la que está provocando una más que tímida respuesta jurisprudencial específica (STS 16/12 de 20 de enero; 467/12 de 11 de mayo; 527/12 de 20 de junio) en torno a la alevosía, cuando el hecho se comete contra la pareja (incluso pariente) habiendo existido una previa discusión entre agresor y agredida. Así se 
ha venido configurando la denominada "alevosía convivencial o doméstica" definida por la STS 16/12 de 20 de enero como la que se basa "en la relación de confianza proveniente de la convivencia, generadora para la víctima de su total despreocupación respecto de un eventual ataque que pudiera tener su origen en acciones del acusado (SSTS 1284/2009, 10 de diciembre y 86/1998, 15 de abril). Se trataría, por tanto, de una alevosía doméstica, derivada de la relajación de los recursos defensivos como consecuencia de la imprevisibilidad de un ataque protagonizado por la persona con la que la víctima convive día a día”.

En esta misma línea, aunque con muchas deficiencias, hemos detectado en este último año un tímido cambio jurisprudencial, admitiendo la posibilidad de que el elemento de desprevención pueda apreciarse en un "segundo tempo" o segunda fase de la ejecución del hecho delictivo, siempre que no provenga de un comportamiento alevoso. Este es el caso de la Sentencia del TS no 474/2011, de 23 de mayo (RJ 2011/5736), de la Sala de lo Penal, Sección 1ª que determina que:

Dentro ya de la alevosía realizada por sorpresa, de modo súbito e inopinado, imprevisto, fulgurante y repentino, la jurisprudencia de la Sala distingue los casos en que se ataca en el momento inicial sin previo aviso, de aquellos otros que también considera alevosos pero en los que la alevosía se tilda de sobrevenida por aparecer en una segunda fase de la ejecución del hecho delictivo. Esta última modalidad de alevosía sobrevenida tiene lugar cuando, aun habiendo mediado un enfrentamiento previo sin circunstancias iniciales alevosas, se produce un cambio cualitativo en la situación, de modo que esa última fase de la agresión, con sus propias características, no podía ser esperada por la propia víctima en modo alguno, en función de las concretas circunstancias del hecho, especialmente cuando concurre una alteración sustancial en la potencia agresiva respecto al instrumento utilizado, el lugar anatómico de la agresión y la fuerza empleada ${ }^{39}$.

En este sentido, el TS, y casi de manera excepcional con respecto al resto de sus pronunciamientos, admite la agravante de alevosía en el siguiente asunto pues entiende se cumplen los presupuestos de indefensión y desprevención de la víctima. Merece la pena la trascripción de parte de la sentencia:

Ciñéndonos ya al caso concreto, en la sentencia de instancia se declara probado con respecto al extremo que ahora interesa dirimir que el acusado "Estacionó el vehículo en la C/....entre los números...., en un lugar que sabía era de paso obligado de Emilia hacia su centro de estudios esperándola durante largo tiempo en su interior sentado en el asiento del copiloto, que daba directamente a la acera, con el cuchillo al cinto en la espalda. Cuando la vio acercarse esperó a que llegara a la altura del vehículo del que salió de manera sorpresiva, abordándola antes de que ella pudiera reaccionar, lo que la llevó a gritar pidiendo auxilio, la agarró con fuerza por el cabello y la arrastró hasta la puerta por la que había salido con intención de obligarla a entrar en el mismo, a lo que Emilia mostró su oposición al tiempo que continuaba pidiendo ayuda, no en vano consiguió de un fuerte golpe que se arrodillara en el suelo con la cabeza apoyada en el asiento del acompañante,

\footnotetext{
${ }^{39}$ En esta misma línea, véanse entre otras: STTS 178/2001, de 13 de febrero, STTS 1214/2003, de 24 de septiembre; STTS 949/2008, de 27 de noviembre; STTS 965/2008, de 26 de diciembre; STTS 25/2009, de 22 de enero; STTS 93/2009, de 29 de enero; STTS 282/2009, de 10 de febrero; STTS 854/2009, de 9 de julio; STTS 1180/2010, de 22 de diciembre.
} vol.08, nº. 03, Rio de Janeiro, 2015.pp. 1441-1480 
cerrándole toda opción de huida con su propio cuerpo que tapaba el hueco que la puerta abierta del vehículo, por una parte, y un árbol allí existente, por otra, dejaban. Pasando de seguido, sin solución de continuidad y con intención de quitarle la vida, a tomar el cuchillo de la cintura y propinarle con fuerza varias puñaladas, hasta un total de 19 , por distintas partes de su cuerpo algunas mortales de necesidad, cesando tan solo cuando la hoja del cuchillo, dada la virulencia con el que se lo introducía en el cuerpo de su víctima después de traspasar en algunos casos la propia ropa que vestía, chocando incluso con materia ósea, se partió y pese a que desde la primera de las incisiones Emilia dejó de oponer resistencia y por tanto cesó en sus gritos al perder la conciencia”. Por consiguiente en el hecho probado, que ha de quedar inalterable a tenor del contenido del escrito de recurso y de la vía procesal utilizada, se afirma que el acusado abordó a su víctima de forma sorpresiva antes de que pudiera reaccionar y la arrastró por la fuerza hasta el vehículo, que tenía allí aparcado. Se da, pues, el supuesto de la alevosía sorpresiva genérica, por cuanto el ataque contra la menor se produjo de forma súbita y repentina, sin que tuviera tiempo ni posibilidad de reaccionar. A esto ha de sumarse que cuando consiguió situar a la víctima junto al vehículo y ésta se hallaba arrodillada al lado del asiento del copiloto, resistiéndose así a que el acusado la introdujera en el coche, el agresor, sin solución de continuidad y con intención de quitarle la vida, extrajo el cuchillo que llevaba a la cintura y le propinó numerosas cuchilladas, hasta un total de diecinueve. No cabe duda, pues, que el recurrente consiguió sorprender a su víctima tanto en la forma de abordarla, en un primer momento, como acto seguido en el modo de agredirla con un cuchillo que hasta que ese momento no había visto la joven. Consiguió por tanto el acusado por la vía del ataque sorpresivo excluir toda posibilidad de defensa de la denunciante y asegurar así la ejecución de la acción homicida, aunque finalmente la intervención quirúrgica practicada evitó un fatal desenlace. Concurren, pues, sin duda alguna los requisitos subjetivos y objetivos de la alevosía sorpresiva, por lo que el motivo de la defensa resulta inviable.

Lamentablemente, la dinámica detectada en nuestros Tribunales en estos últimos años, pese a los avances legislativos al respecto sigue siendo la denunciada en este trabajo, lo que nos obliga a cuestionarnos la eficiencia de una normativa gestada con el propósito de erradicar la violencia de género como lacra social que es y la (ir)responsabilidad de una ciencia jurídica que insiste - sin demasiado control por parte de la Filosofía del Derecho $^{40}$ - en aplicar teoremas matemáticos al Derecho. En este sentido, cronológicamente in crescendo, veánse ST Audiencia Provincial de Madrid de 21 de octubre de 1992; STTS de 25 de julio de 2000; ST de la Audiencia Provincial de Madrid (Sección 1a) no 458/2005, de 17 de Octubre, JUR 2005/257752, ST de la Audiencia Provincial de Girona (Sección 3a) no 590/2005, de 10 de junio, ARP 2006/56; ST de la Audiencia Provincial de Zamora (Sección 1a), no 10/2010, de 15 de abril, ARP 2010/636; ST de la Audiencia Provincial de Badajoz (Sección 1a), no 47/2011, de 21 de noviembre, (ARP 2011/1371) así como la sentencia no 474/2011, de 23 de mayo, RJ $2011 / 5736$.

\footnotetext{
${ }^{40}$ A excepción de algunas voces, minoritarias, de la Filosofía del derecho señaladas en una nota anterior, lo cierto es que ni la Ciencia jurídica repara con seriedad en ellas, ni esta misión ha sido abrazada como impostergable por parte de la Filosofía del derecho. A ello debemos sumarle el preocupante papel residual que progresivamente está adquiriendo la disciplina en los estudios jurídicos, problema que sin duda -entiendo- debe ser tratado y revisado de manera urgente por la Academia.
} vol.08, nº. 03, Rio de Janeiro, 2015.pp. 1441-1480 


\section{LOS CONOCIMIENTOS ESPECIALES DE LA VÍCTIMA VERSUS EL PRINCIPIO DE PRESUNCIÓN DE INOCENCIA DEL AGRESOR}

Otro aspecto reseñable reside en el conflicto que tradicionalmente se produce entre la supuesta violación del principio de presunción de inocencia ${ }^{41}$ - principio tradicionalmente alegado por la defensa del agresor-, la sola denuncia explicitada por la agredida denunciando la situación de violencia física y psíquica a la que se encuentra sometida y el dato criminológico de los expertos y expertas médicas que viene a corroborar que el maltratador dirige los golpes hacia cabeza (rotura de tímpano), espalda y pecho ${ }^{42}$, con el fin de que el pelo y la ropa cubra las lesiones acaecidas en estas zonas. Las consecuencias psíquicas aún son más difíciles de percibir. Las deficiencias en la investigación de oficio, según el último Informe de Amnistía Internacional de noviembre de 2012, se incrementan cuando la violencia no es física, ni reciente, ni documentada con un parte de lesiones (violencia sin marcas), lo que queda en impunidad absoluta pese al enorme impacto en la integridad psicológica de las mujeres. Si a ello le sumamos el dato de que las mujeres maltratadas -reacias a dirigirse al profesional médico-sanitario y a presentar denuncias por miedo, vergüenza o resignación- cada vez que acuden a éste lo hacen progresivamente con episodios más graves de violencia, habrá que plantearse de manera crítica si la respuesta jurídica previene y protege a las víctimas de agresiones futuras o si por el contrario, el exceso de formalismo y de requisitos casuísticomatemáticos abandonan a mujeres y menores a la suerte de agresor.

\footnotetext{
${ }^{41}$ No obstante, llama la atención la alegación de vulneración del principio de presunción de inocencia en supuestos como los acaecidos en el día de autos de la STTS de 9 de octubre de 2000, en que la defensa argumenta que "no se tiene certeza que el acusado hubiera podido actuar con alevosía, además de no haberse acreditado el aseguramiento del golpe y las contradicciones anteriormente relatadas". Al respecto, el Ministerio Fiscal expone que "los hechos están acreditados por la admisión del acusado, que declaró haber apuñalado a su esposa por la espalda, aún cuando en el plenario rectifique y manifieste no recordar la agresión; contamos también con el testimonio de sus hijos y los informes periciales médicos, junto al acta de inspección ocular". Los hechos probados recogidos en la Sentencia no requieren mayor comentario: "el acusado, como consecuencia de un episodio de discusiones con su esposa, que determinaron que abandonase su domicilio conyugal, volvió a él, en la tarde del día 15 de noviembre de 1997, franqueándole la puerta un hijo suyo, quedándose en la vivienda, una vez que su hijo se marchó. Poco más tarde, llega su hija Raquel, y tras discutir con ella, la golpea en la cara, por lo que se refugia en la habitación; en estas circunstancias, Raquel escuchó como su padre rebuscaba algo en una caja de herramientas y después en la cocina, más concretamente en el cajón donde se encontraban las cuberterías. Poco después, entró en el domicilio antes dicho su esposa, Ana María, que residía temporalmente en una casa de acogida para mujeres maltratadas, aunque frecuentaba el piso para proveer al cuidado de sus dos hijos, y tras discutir con el acusado, éste la llamó para que acudiese a la habitación matrimonial, que se encontraba enfrente de la ocupada por Raquel, escuchando ésta instantes después la voz de su madre que decía "Raquel que me mata", saliendo de su habitación justo en el momento en que su padre salía de la habitación conyugal, y después su madre, con un cuchillo de unos vein te por tres centímetros de hoja clavado en la espalda voluntariamente por aquél con ánimo de causarle la muerte, diciendo la madre "quítamelo..... quítamelo...”, lo que así hizo, desplomándose la madre en el suelo y saliendo la hija al rellano en petición de auxilio.

${ }^{42}$ El estudio realizado por Muellerman en 1996 sobre nueve mil mujeres que acudieron al Servicio de Urgencias de diez hospitales demostró que las mujeres maltratadas suelen presentar las lesiones en la cabeza y en el tronco, frente a las mujeres que acudieron a urgencias sin haber sufrido agresión por parte de sus parejas, cuyas lesiones se focalizaban en la columna vertebral y extremidades inferiores. Asimismo, y según un estudio de STARK, E., FLITCRAFT, A. Y FRAZIER, W, "Medicine and patriarcal violence: The social construction of a "private” event", International Journal of Health Service, 1979, 9, pp. 461-493, las mujeres maltratadas tenían una probabilidad 13 veces más alta de tener lesiones en pechos, tórax o abdomen que las víctimas de otros accidentes.
} vol.08, nº. 03, Rio de Janeiro, 2015.pp. 1441-1480 
En este sentido, estamos de acuerdo con la STTS de 24 de junio de $2000^{43}$ en su FJ no 2 cuando nos recuerda que "Existe al respecto una consolidada doctrina de esta Sala -SSTS de 26 de mayo de 1993, 1 de junio de 1994, 14 de julio de 1995, 17 de abril, 13 de mayo de 1996, no 111/99 de 30 de enero, no 486/99 de 26 de marzo y no 711/99 de 9 de julio, entre otras- según la cual, la declaración de la víctima es, por sí sola, capaz de provocar el decaimiento de la presunción de inocencia siempre que en dicha declaración no aparezcan sospechas de parcialidad o intereses ajenos a la mera expresión de la verdad de lo ocurrido, y en tal sentido como aspectos que no requisitos- a tener en cuenta para contrastar la veracidad de tal declaración se ha referido esta Sala a la ausencia de incredibilidad absoluta, a la verosimilitud del relato y a la persistencia de la imputación. Como ya recordaba la sentencia de esta Sala de 24 de noviembre de 1987, nadie ha de sufrir el perjuicio de que el suceso que motiva el procedimiento penal se desarrolle en la intimidad entre la víctima y el inculpado. En otro caso, se provocaría la más absoluta de las impunidades". En esta línea también se pronuncia el Juzgado de lo Penal no 1 de Cartagena en Sentencia 26/2013 de 18 de febrero, al recordar que la exigencia de verosimilitud:

Habrá de ponderarse adecuadamente en delitos que no dejan huellas o vestigios materiales de su perpetración (art. 330 LECrim); puesto que el hecho de que en ocasiones el dato corroborante no pueda ser contrastado no desvirtúa el testimonio si la imposibilidad de la comprobación se justifica en virtud de las circunstancias concurrentes en el hecho.

El problema se plantea cuando las mujeres son especialmente visibilizadas, tienen que probar y comprobar su testimonio (Sentencia de la Audiencia Provincial de Córdoba (Sección 1a), en sentencia de 5 de noviembre de 2007) y se ven obligadas a impulsar el proceso a partir de evidencias (en tanto que no disponen de otros testimonios que lo corroboren) promoviendo actuaciones, a fin de que las investigaciones avancen y los procedimientos no sean sobreseídos por falta de pruebas. Si a ello le sumamos ${ }^{44}$ la falta de diligencia en la investigación de oficio, la insuficiente y, en ocasiones, ineficaz labor de la Fiscalía y el rechazo de los jueces de los asuntos por insuficiencia probatoria, el resultado no puede ser menos halagüeño para las mujeres que al final se animan a denunciar. El Informe de Amnistía Internacional de noviembre de 2012 apunta además a la predisposición de los operadores jurídicos en general, cargados de prejuicios sexistas, a las sospechas infundadas relacionadas con la falsedad de la denuncia e incluso, en los casos de mujeres extranjeras en situación irregular, la tendencia a valorar como más que posible la instrumentalización de la denuncia para obtener autorización de residencia y otros beneficios económicos y sociales.

Al presentarse el caso de esta manera, los tres parámetros o líneas de acción tomadas por los tribunales solo serán entendidos a efectos de admitir la prueba, debiendo pasar un segundo "filtro" en el que se valorará la

\footnotetext{
${ }^{43}$ En esta línea, merecen la pena mencionarse algunos pronunciamientos de la "jurisprudencia menor", a saber: Sentencia de la Audiencia Provincial de Sevilla de 10 de enero de 2003; de Madrid de 28 de febrero de 2003; de Valladolid de 11 de marzo de 2003 y de la Audiencia Provincial de Alicante de 20 de marzo de 2003.

${ }^{44}$ Ver Informe de Amnistía Internacional de noviembre de 2012.
} 
calidad de dicha declaración con las demás pruebas aportadas al proceso. Como indica la STTS 230/2010, de 19 de marzo (RJ 2010, 1474) el contenido de una testifical que supere el triple filtro indicado (credibilidad, verosimilitud y persistencia), no debe ser tenido como válidamente inculpatorio. Esta es la línea seguida por las sentencia de la Audiencia Provincial de Madrid (Sección 2a) no 113/2012, de 9 de febrero, ARP 2012/444 que afirma que "(a)dquiere pues similar importancia explicar por qué se cree a un testigo como dar cuenta del porqué no se cree al testigo que afirma hechos contrarios” o la ST de la Audiencia Provincial de Córdoba (Sección 1ª nº 860/ 2010, de 16 de noviembre (ARP 2011/1094, entre otras que además, basándose en anterior sentencia del TS de 19 de diciembre de 2003 (RJ 2003, 9316) recoge un apunte, a mi parecer peligroso por prejuicioso y sexista; a saber:

A nadie se le escapa, dice la STS 19.12.2003 (RJ 2003, 9316), que cuando se comete un delito en el que aparecen enemistados autor y víctima, en estas infracciones que ordinariamente se cometen en la clandestinidad, puede ocurrir que las manifestaciones de esta última (la víctima) tengan que resultar verosímiles por las concretas circunstancias del caso. Es decir, la concurrencia de alguna circunstancia de resentimiento, venganza, enemistad o cualquier otro motivo ético y moralmente inadmisible es solamente una llamada de atención para realizar un filtro numeroso de sus declaraciones, no pudiéndose descartar aquellas que, aún teniendo esas características, tienen solidez, firmeza y veracidad objetiva. Lo que importa es la razonabilidad en la convicción del Tribunal sobre la cual ha de argumentarse expresamente en la sentencia condenatoria. El examen de tales tres elementos es solo un método de trabajo que esta Sala viene mostrando como una posibilidad arraigada de las dificultades que con mucha frecuencia, se encuentran los Tribunales en estos casos. STS 1-12$2004\left(\right.$ RJ 2005, 466) ${ }^{45}$.

En relación a las versiones contradictorias o insuficientes de la víctima, -propias del bloqueo postraumático, y de la necesidad de seguimiento experto médico-psicológico-, a efectos de no tenerlas en cuenta siquiera para la determinación de la existencia de indicios de delito o falta a efectos del art- 54 ter LECrim. se pronuncia la Audiencia Provincial de Madrid en Auto de 5/2005, de 19 de enero, RJA marginal 2005/246848:

La apelante indica en su solicitud en sede policial que ha recibido amenazas de muerte de su marido, con el que está en trámites de separación, sin embargo en su declaración ante el Juzgado de Instrucción no es capaz de concretar ninguna de esas amenazas, ni describe ningún hecho susceptible de constituir algún delito contra la vida, la integridad física o moral, la libertad sexual o la libertad y seguridad. Tan sólo se refiere a una situación ocurrida dos años antes (unas amenazas con un arma) de forma vaga. Al no aparecer indicios de ninguno de estos delitos, tampoco es posible apreciar la existencia de una situación objetiva de riesgo para la víctima.

Creemos fundamental admitir los conocimientos especiales de la víctima y abogamos por entender la amenaza como una agresión en sí misma. De otro modo, podríamos llegar a situaciones de indefensión jurídica o cómicas -lamentablemente- como la Sentencia del Juzgado de Instrucción no 3 de Roquetas de Mar, de 26 de

${ }^{45}$ ST de la Audiencia Provincial de Córdoba (Sección 1a) no 860/ 2010, de 16 de noviembre (ARP 2011/1094. vol.08, n. 03, Rio de Janeiro, 2015.pp. 1441-1480 
septiembre de 2000 en la que se absolvía al inculpado de una falta de amenazas "pues las versiones ofrecidas por los implicados son opuestas" y porque "la denuncia fue instrumento para conseguir la asistencia" del Instituto Andaluz de la Mujer ${ }^{46}$, o como la Sentencia de 13 de abril de 2000, del Juzgado de 1a Instancia e Instrucción de $\operatorname{Loja}^{47}$, absolutoria al excluir la declaración de la víctima por "falta de concurrencia al acto del juicio del único testigo de los hechos" y "a un somero análisis" de las relaciones previas entre acusado y víctima.

Toda esta situación se agrava aún más al contrastarla con algunos datos sociológicos: la víctima no siempre acude a juicio (43\%), ni cuando lo hace ratifica su denuncia (45\%), un $11 \%$ asiste y perdona al agresor y el $1 \%$ restante reconoce agresiones mutuas ${ }^{48}$. Algún dato reciente ${ }^{49}$ resulta especialmente preocupante: en relación con 2007, el número de renuncias ha aumentado un 29\%, especialmente a partir de 2009º; así como ha caído el número de denuncias en estos últimos años con respecto a la dinámica conseguida desde la aprobación de la Ley Integral. En 2011 se archivaron más del 45\% de las denuncias por violencia de género, a nivel estatal y autonómico, y la tendencia es in crescendo. De este modo, si en 2011 se concedieron 18.349 órdenes de protección, en $2014^{51}$ han caído a 15.438. Son, como vemos, casi tres mil menos. La protección de las víctimas de violencia de género ha ido disminuyendo año tras año ${ }^{52}$. No en vano, en los últimos tres años, hemos asistido a un recorte presupuestario de un $22 \%$. Asimismo (o en consecuencia), se ha disparado el número de sobreseimientos judiciales y ha descendido notablemente la concesión de órdenes de protección. La mayoría de las sentencias absolutorias se dictan por falta de pruebas. No obstante, la violencia oculta, esto es la no denunciada pero detectada a través de estudios estadísticos, representa un 73\% del total de los abusos. Los datos cantan: en 2013, 53 mujeres fueron asesinadas en España. El 93\% no contaba con ninguna medida de protección en vigor a pesar de que el 31\% había denunciado previamente malos tratos. Las valoraciones de riesgo extremo han bajado un $38 \%$ en los últimos años

\footnotetext{
${ }^{46}$ Dice así la Sentencia del Juzgado de Instrucción no 3 de Roquetas de Mar, de 26 de septiembre de 2000, siendo Juez el Sr. Fernández Ayuso: "No ha quedado acreditada la comisión de la falta de amenazas que se imputa al denunciado, pues las versiones ofrecidas por los implicados son opuestas, unido a que la testifical practicada a instancia de la parte denunciante no aclara la posible responsabilidad del imputado, sino que viene a despejarla, pues manifiesta que fue a hablar con la letrada del Instituto de la Mujer aconsejándosele que era precisa denuncia de los hechos a fin de poder prestar asistencia y ayuda, hecho éste que unido a la estrecha relación entre la testigo y la denunciante, revela que la denuncia fue instrumento para conseguir la citada asistencia”.

${ }^{47}$ Sentencia de 13 de abril de 2000, del Juzgado de $1^{a}$ Instancia e Instrucción de Loja, siendo Jueza la Sra. Moreno Verdejo.

${ }^{48}$ ASOCIACIÓN DE MUJERES JURISTAS THEMIS, Respuesta penal a la violencia familiar, opus cit., pp. 30-31.

${ }^{49}$ Ver Informe de Amnistía Internacional de noviembre de 2012. Asimismo, véase CGPJ, Datos de denuncias, procedimientos penales y civiles registrados, órdenes de protección solicitadas en los juzgados de violencia sobre la mujer (JVM) y sentencias dictadas por los órganos jurisdiccionales en esa materia en el año 2011, CGPJ, Madrid, 2011.

${ }^{50}$ En el año 2008, de un total de 142.125 denuncias, renunciaron al proceso 16.100 mujeres. En 2009, de un total de 135.540 denuncias, 16.762 mujeres renunciaron al proceso. Para más información, véase http://www.juntadeandalucia.es/export/drupaljda/Violencia_Genero_Ficheros_DENUNCIAS Y RENUNCIAS.pdf

${ }^{51}$ Datos recogidos por LOURIDO, M., en http:// cadenaser.com/ser $(\overline{20} 15,02 / \overline{16} /$ sociedad

${ }^{52}$ No obstante, el Instituto Andaluz de la Mujer acogió a 250 mujeres de violencia en peligro de muerte en 2014: 115 mujeres y 135 menores a su cargo a través del servicio integral de atención y acogida, según datos del propio IAM. Vid. Diario Córdoba de 9 de febrero de 2015, consultable en http://www.diariocordoba.com/noticias
} 
y un $28 \%$ las de riesgo alto. Además sólo están implantados 710 dispositivos de seguimiento para controlar a los maltratadores de las 3.000 disponibles.

La conclusión suele ser que el testimonio incriminatorio de la víctima, vaya o no acompañado de otras pruebas, sólo supone la condena del agresor en algo menos de la mitad de las ocasiones; con lo cual la "palabra de uno contra la del otro" o la contradenuncia ${ }^{53}$, implica la absolución del agresor en tal porcentaje ${ }^{54}$ en el primer caso, o la negociación entre partes, en el segundo; así como la zona del cuerpo golpeada (el agresor golpea donde no deja marcas), o la dificultad probatoria del daño moral y psicológico implica igualmente la absolución o la sola condena del inculpado - con la anterior regulación ${ }^{55}$ - por falta que no por delito; o la inaplicación del 173.2 como violencia habitual, al verse compelidas las más a ceñirse al hecho puntual. Esta misma línea jurisprudencial sigue manteniéndose en la actualidad, exigiéndose que sea la propia víctima quien pruebe la veracidad de su relato (Sentencia de la Audiencia Provincial de Córdoba (Sección 1a), en sentencia de 5 de noviembre de 2007).

Frente a ésta, afortunadamente la Sentencia de la Audiencia Provincial de Jaén, Sección segunda, de 18 de enero de 2002, se pronuncia en la línea por nosotros defendida, y se condena al inculpado como responsable de un delito de malos tratos psíquicos habituales, otro de amenazas y tres faltas de injurias leves "fundamentalmente por la propia testifical de la víctima", ex esposa del acusado, "que reúne los presupuestos exigidos jurisprudencialmente para otorgarle credibilidad y validez en orden a constituir prueba de cargo suficiente para desvirtuar el principio de presunción de inocencia". Las frases proferidas por el acusado hacia su esposa en varias ocasiones tales como "zorra, puta", "te tengo que rociar con gasolina", "te tengo que quitar la vida", así como los distintos episodios sistemáticos de violencia física y psíquica durante el matrimonio y tras la separación -episodios, algunos, denunciados y condenados- crearon "una atmósfera irrespirable y un clima sistemático de maltrato". Asimismo, y según informes periciales, la víctima "padece el Síndrome de la Mujer Maltratada, consistente en sensación de angustia, miedo, trastornos del sueño, entre otros, apuntando como único origen de los mismos los malos tratos físicos y psíquicos provocados por el marido" ${ }^{\text {. }}$.

\footnotetext{
${ }^{53}$ A las dificultades probatorias de una agresión que acontece en la intimidad del hogar, debe sumarse la creciente tendencia por parte del agresor de presentar contradenuncia como estrategia procesal para intentar alcanzar una negociación que propicie la no comparecencia de la mujer en el juicio. Hablamos de una revictimización de la mujer pues no sólo será agredida sino también denunciada por su pareja o expareja. Según el Informe sobre víctimas mortales de la violencia de género y de la violencia doméstica en el ámbito de la pareja o expareja del CGPJ en 2011, tres de las mujeres asesinadas en 2010 habían sido denunciadas por sus asesinos.

${ }^{54}$ Sentencias como la de la Audiencia Provincial de Gerona de 31 de enero de 2003, o la de la Audiencia Provincial de La Coruña de 25 de marzo de 2003, son buen ejemplo de rechazo de credibilidad de las declaraciones de la víctima y de carecer de la corroboración necesaria.

${ }^{55}$ Sirva como ejemplo la Sentencia de 17 de julio de 2000, del Juzgado de lo Penal no 8 de Málaga, que aun admitiendo los conocimiento especiales de la víctima, condenaba por falta que "existe al haberse causado lesiones para cuya sanidad sólo ha sido precisa primera asistencia médica con la intencionalidad lesiva que la zona del cuerpo afectada por los actos (cabeza, cuello, manos) evidencian”. Sentencia de 17 de julio de 2000, del Juzgado de lo Penal no 8 de Málaga, siendo Juez, el Sr. Macho Macho

${ }^{56}$ Sentencia de 18 de enero de 2002, de la Excma. Audiencia Provincial de Jaén, Sección 2a, siendo Ponente el Ilmo. Sr. José Requena Paredes.
} 
La importancia de un buen informe pericial médico destaca por disipar y ayudar a entender al operador último del Derecho cualquier duda al respecto de las formas en que se manifiesta y vive la violencia de género (con bloqueos y aparentes contradicciones que afectan a la verosimilitud del testimonio), además de ayudar a la víctima a desentrañar los matices de la violencia normalizada por ella, fortaleciendo su capacidad de resilencia y por ende su confianza en el procedimiento judicial. Este es el caso de la reciente Sentencia del Juzgado de lo Penal $n^{\circ} 1$ de Cartagena, no 26/2013 de 18 de febrero ${ }^{57}$, o la Sentencia del TS no 1139/2009, de 30 de octubre, RJ 2010/991, Sala de lo Penal (Sección 1a):

En el caso de la Sentencia recurrida, que condena al acusado como autor de lesiones por imprudencia grave, la Sala no sólo contó con la declaración de la víctima sino con los informes periciales médicos sobre la grave lesión en un ojo sufrido por ésta, objetivamente corroborante de su testimonio, que a su vez ni contiene contradicciones ni evidencia motivaciones espurias. En efecto expresar una vez la creencia de que su marido en el forcejeo sí tenía intención de hacerle daño, y decir en otra que dentro de la pelea la lesión fue un accidente no es una contradicción de testimonio sino una modificación de su personal opinión o creencia acerca del propósito del acusado, que puede resultar de la reflexión y reconsideración sobre su intención, lo cual no es contradictorio respecto a la material narración de lo materialmente sucedido. Tampoco es una contradicción que afecte al testimonio sobre lo sustancial del hecho referir que después del incidente su marido no la amenazó ni la molestó pero también reconocer que le tiene miedo porque a las dos semanas entró en la casa borracho pidiéndole la ropa. Menos aún que de tales expresiones o afirmaciones resulte evidenciado ninguna animadversión o motivación espuria que derivada de circunstancias anteriores al hecho denunciado hagan dudosa la veracidad de su declaración.

Asimismo, si importante son los informes médicos que pueden acompañar, ayudar y/o corroborar el testimonio de la víctima, -o incluso suplir, con su testimonio, la dispensa legal de no declarar de la víctima contra su pareja o expareja otorgada por el art. 416 de la LECrim- no son menos decisivos los informes aportados por los Cuerpos y Fuerzas de Seguridad del Estado u otros testimonios periféricos que podrían dotar de entidad el supuesto perseguido. En esta línea nos encontramos la ST de la Audiencia Provincial de Madrid (Sección 27a), nº 1011/2011, de 30 de noviembre, JUR 2012/22712, destacada precisamente por todo lo contrario.

En el presente supuesto no se ha practicado en el plenario una prueba de cargo enervatoria de la presunción de inocencia del acusado, que permita sostener un fallo condenatorio. De esta forma, la denunciante y presunta víctima se acogió en el plenario a la facultad que a no declarar contra su pareja le otorga el art. 416 de la LECrim (LEG 182, 16), el acusado de otra parte, afirmó no recordar lo que dijo al hallarse embriagado y el Guardia Civil no J-35913-F no recordaba las expresiones que el acusado profirió afirmando que estaba bebido, y profirió unas frases amenazantes y solo a las preguntas del Ministerio Fiscal que le preguntó si dichas frases pudieran ser

\footnotetext{
${ }^{57}$ Hablamos de dos informes médicos donde valoran las lesiones de la víctima incompatibles con un frenazo de coche -tal y como alegaba el agresor-, al no existir latigazo cervical; y destaca un hematoma en la pantorrilla derecha, al intentar la víctima salir del coche donde el agresor la golpeaba.
} 
atentatorias contra su vida, contestó que creía que sí y que las dijo en un estado de exaltación y del juez a quo sobre si lo consignado en el atestado es lo que oyó, manifestó que sí. Con sólo esta declaración del Guardia Civil, que no recordaba con exactitud lo manifestado por el acusado, y que solo resulta incriminatoria, por la pregunta que directamente formuló el juzgador a quo, sobre si no podía precisar qué tipo de amenazas efectuó, y si la expresión que refería en el atestado era la que escuchó aunque no la recordase ahora, fue contestada por el Guardia Civil, con "sí, sí efectivamente", resulta para este Tribunal insuficiente para avalar la tesis incriminatoria mantenida por la acusación. Procede pues absolver al procesado del delito de amenazas por el que venía siendo acusado y era objeto de acusación.

Ídem sucede en Sentencia de la Audiencia Provincial de Madrid (Sección 27a) no 832/2012, de 26 de julio, JUR 2012/332223, donde se percibe claramente el terror de la víctima ante dos agresiones diferentes en tiempo que sin duda afectan a las "contradicciones" de su declaración, y a su dispar reacción en torno a su primera e inmediata denuncia y a la tardanza de ésta en la segunda agresión. Sólo un correcto conocimiento de las características y manifestaciones de la violencia de género en el contexto de pareja permitiría visibilizar las normales reacciones de pavor y miedo, propias del síndrome psiquiátrico de la mujer maltratada, y no calificarlas de contradicciones invalidantes de la verosimilitud de su testimonio. En este asunto, además, aun cuando las agresiones se realizaron en lugar público -y no en la intimidad del hogar- lamentablemente el testimonio periférico brilla por su ausencia, lo que abandona a la mujer a su suerte, no permitiendo atribuir a sus declaraciones el valor probatorio de cargo que sí se le otorgaba en la sentencia de instancia. Y es que, "aun cuando afirme que iba acompañada, o que fue al Hospital porque sus amigos la convencieron, no aporta datos de sus amigos, ni se ha recibido declaración de ninguno de ellos, con lo que no existe ninguna otra prueba de cargo que sus solas declaraciones".

Pero, en este caso, ni nos encontramos ante declaraciones persistentes, ni podemos estimarlas suficientemente corroboradas desde el punto de vista objetivo.

Como sostiene el recurrente en su escrito, cuando Da María Cristina denuncia por primera vez, los hechos acaecidos en el interior del Bar Antiquarium -por cierto, inmediatamente después de que ocurran- en la Comisaría de Policía de Alcobendas, lo que refiere es que ha entrado en dicho establecimiento y ha visto en él al acusado, con unos amigos, y que, aunque tenía una prohibición de aproximarse a ella, dado que conoce al dueño del bar, hizo caso omiso, y, a los pocos minutos, él se acercó a ella y le dijo que era una fresca, y que tuviera cuidadito con él, y que si quería, lo arreglaban en la calle. Sin embargo, cuando solo cinco días después comparece ante el Juzgado de Instrucción, modifica su versión de los hechos, para decir que es ella la que, al ver que Patricio estaba dentro del bar, se dirigió a él para decirle que se fuera o que llamaría a la policía, momento en que él empezó a insultarla y a amenazarla con que la iba a volver a pegar, justificando su cambio de versión en que ella está muerta de miedo, y “algunas veces no se acuerda". Y dice que él se va cuando ella hizo el gesto de llamar por teléfono a la policía. Y en el acto del juicio oral, vuelve a cambiar su versión de los hechos, pues declara que ella entró en el Pub con un grupo vol.08, nº.03, Rio de Janeiro, 2015.pp. 1441-1480 1464 
de amigos, y él, al verla se puso a insultarla y a amenazarla, y se lo dijo al del Bar, que no le hizo caso. Respecto de los segundos hechos, que ella no denunció sino hasta las 23.21 horas, esto es, casi 45 horas después de su acaecimiento, cuando acudió a la Comisaría de Policía, de nuevo, lo que refiere es que iba a dormir a la casa de una amiga, y que, cuando se encontraba en la CALLE000, donde ella vivía, él la abordó por detrás y le propinó dos puñetazos en la cara. Y en el Juzgado de Violencia Sobre la Mujer, también respecto de esta agresión cambia su relato para asegurar que le da un solo puñetazo, que la lesiona el pómulo y el labio, y reitera "todo lo hizo con el mismo golpe". Y en el juicio oral, mantiene que le dio un solo puñetazo, pero asegura que donde se dirigía no era a casa de una amiga, sino a su casa. Y cuando el Letrado de la defensa le pone de manifiesto tal contradicción, sin alterarse, de ningún modo, refiere que no hay ninguna contradicción, ya que ella se encontraba viviendo entonces en casa de una amiga, con lo que vuelve a incurrir en una contradicción más, puesto que, cuando en el Juzgado de Instrucción se le pregunta por la tardanza en ir a recibir asistencia médica y, más aún, a denunciar, lo justifica en que, tras la agresión ella se fue a su casa. En el acto del juicio oral refiere que ella tarda tanto tiempo en ir a recibir asistencia médica -a las 22.17 horas del día 6, esto es, más de 19 horas después del momento en que dice que acaecieron los hechos- y en acudir a la Comisaría de Policía a denunciar -a las 23.21 horas del día 7 de febrero- porque estaba aterrada y no se atrevía a salir de casa. Pero resulta difícil admitir como plausible tal explicación cuando, por un hecho de menor gravedad, acaecido ni siquiera dos horas antes, cuando ha coincidido con él en un bar, y, según su relato, se ha dirigido a ella, llamándola fresca y diciéndola que tuviera cuidadito con él, antes de marcharse del bar, en cuanto ella le advierte de que llamará a la Policía, acude, inmediatamente, a interponer la denuncia. Por otro lado, la corroboración objetiva, de carácter periférico que podrían suponer las lesiones, que, desde luego pueden resultar incompatibles con la dinámica de causación que ella refiere -uno o dos puñetazo- resulta notablemente disminuida por la circunstancia del importante lapso temporal que transcurre entre el momento de su supuesto acaecimiento, y aquel en el que tiene lugar su constatación en el Hospital Infanta Sofia.

No obstante la desconfianza apriorística del testimonio de la víctima queda constatada incluso en sentencias donde entiende causa de contradicción, razones ridículas por su irrelevancia. Este es el caso de la Sentencia de la Audiencia Provincial de Madrid (Sección 27a) no 63/2012, de 28 de junio, ARP 2012/760, donde una supuesta contradicción entre el testimonio de la víctima y su hermana, inhabilita ambos testimonios. En este sentido, la víctima refiere que el acusado le dijo "te voy a matar", mientras que su hermana señala que éste profirió "os voy a matar a todos". Entendemos que se ha tomado de manera muy estricta y estrecha, la necesaria coincidencia que deben tener ambas declaraciones, habida cuenta que el decir "os voy a matar a todos" incluye también a la víctima, no habiendo una diferencia sustancial, además de haber absoluta coincidencia en el relato de las demás agresiones recogidas en el relato fáctico materia de imputación ("que la iba a hundir, que la iba a dejar sin nada, y que la iba a dejar hasta sin el perro").

En el caso que nos ocupa, la declaración incriminatoria de la denunciante, si bien ha sido persistente durante todo el procedimiento, ha carecido, contrariamente a lo expuesto por el juzgador "a quo", de la corroboración vol.08, no. 03, Rio de Janeiro, 2015. pp. 1441-1480 1465 
periférica del testimonio de su hermana Reyes. Al no ser éste coincidente con el de la perjudicada respecto de la determinación de las frases intimidatorias que se atribuyen al acusado y constituirían el tipo penal por el que se le condena en la resolución recurrida. Así: tanto el acusado como la víctima han coincidido en que la denunciante había cambiado la cerradura del domicilio común impidiendo así la entrada a la vivienda del acusado. Coincidieron el recurrente y Reyes en referir un altercado entre ambos que no fue objeto de acusación en el que se habrían proferido mutuos insultos. Sin embargo, aunque Reyes sostiene que el acusado le dijo "os voy a matar a todos", estas manifestaciones no coinciden con las frases intimidatorias de que relató haber sido objeto la víctima al referir que desde fuera de la casa el acusado se dirigió a ella diciéndole "te voy a matar". Estas manifestaciones no concuerdan con lo referido por Reyes al decir la testigo (precisamente coincidiendo con el acusado) que éste no podía ver desde fuera de la casa a su pareja porque "hay fraileros y no se ve". Ante tales amenazas y no coincidiendo siquiera la víctima y su hermana en si las amenazas de muerte que se atribuyen al acusado se dirigían a todos o únicamente a Esther, no puede estimarse acreditado que el recurrente las pronunciase. Sí coincidieron las hermanas en relatar que el acusado dijo a Esther que la iba a hundir, que la iba a dejar sin nada, y que la iba a dejar hasta sin el perro, pero estas expresiones (no recogidas, de otra parte, en el relato de los Hechos Probados) no constituirían el tipo penal del artículo 171.4 del Código Penal (RCL 195, 3170 y RCL 1996, 777) por el que se condena la apelante (...).

\section{EL DERECHO TIENE GÉNERO}

\section{La habitualidad: concepto y evolución de la doctrina jurisprudencial}

La exigencia de habitualidad sigue siendo un ejemplo de cómo el Derecho tiene género, tanto en las reflexiones que la Ciencia jurídica ha realizado en torno a ella, como a la aplicación que se ha venido realizando de esta exigencia típica del 173.2 (antiguo art. 153.2) del CP. La primera cuestión que se nos plantea es determinar qué se entiende por habitualidad. El legislador penal -quien en el anterior Código Penal de 1989 aludía a ella pero sin definirla-, especifica en el punto 3 del art. 173 -insistiendo en lo dispuesto en el antiguo párrafo 2 del art. 153que: "Para apreciar la habitualidad a que se refiere el párrafo anterior, se atenderá al número de actos de violencia que resulten acreditados, así como a la proximidad temporal de los mismos, con independencia de que dicha violencia se haya ejercido sobre la misma o diferentes víctimas de las comprendidas en este artículo, y de que los actos violentos hayan sido o no objeto de enjuiciamiento en procesos anteriores". Curiosamente, y pese a ser uno de los aspectos más criticados por nosotros y que reclamaban una reforma penal urgente -si no su eliminación, aspecto que debía haber sido tratado en la última reforma del Código Penal de 29 de septiembre de 2003- el legislador no ceja en su empeño de mantenerlo como requisito constitutivo del tipo.

La habitualidad que aparece en el tipo como constitutiva de la acción punible ha generado históricamente diversidad de opiniones respecto a su interpretación. No obstante, sí intentó concretar su 
contenido y de manera taxativa en el art. 161 del Proyecto de L.O de C.P de 1992”. A los efectos de este artículo, existe habitualidad cuando el culpable hubiere sido condenado por tres o más delitos o faltas de lesiones contra las personas a que se refiere el apartado anterior, en los cinco años precedentes a la comisión de la nueva infracción penal"58.

Esto es, para poder ser castigado con la pena de prisión de 6 meses a 3 años, sin perjuicio de las penas que le pudiera corresponder por el resultado que en cada caso se causare, se requería que el que ejerce la violencia hubiera sido ya condenado, no por uno, sino por tres o más delitos o faltas de lesiones, y en el plazo prescriptivo de cinco años, inmediatamente anteriores al momento de la comisión del ilícito penal.

En otras palabras, habría que esperar a que el cónyuge agresor propine varias palizas sobre el otro, o sobre los hijos sometidos a tutela o guarda; y que estas palizas hubieran sido denunciadas, enjuiciadas y condenadas por el juez en cuestión, en un número igual o superior a tres y en un período de tiempo inferior a cinco años. Esta exigencia muestra nuevamente -y conectando con los delitos referidos al inicio de nuestra exposición- cómo la violencia conyugal sigue jugando dentro del ámbito familiar como un parámetro normal ${ }^{59}$. Violencia de hombre hacia mujer, que debe controlar a un ser débil y rebelde, así como a sus hijos, que de vez en cuando claman en silencio "un toque" de fuerza física y psíquica. Sólo dicho razonamiento justificaría las duras exigencias de violencia exigidas por el legislador. Y si no, ipor qué se requiere la condena de tres o más delitos o faltas de lesiones en el plazo prescriptivo de cinco años? ¿Cuántas palizas debe el agresor propinarle a la agredida -en este caso, mujer; en otros casos, hijos ${ }^{60}$ - para que se denuncien algunas -que, desde luego, no todas- se enjuicien y prosperen, culminando en condena? ¿Acaso el legislador no conoce la famosa lentitud de la justicia? ¿Habrá que esperar a que la mate en una de sus múltiples palizas; o la mutile o la incapacite para siempre?

Afortunadamente, la redacción del Proyecto de L.O. de C.P. de 1992 no prosperó, debiendo ser el juez quien determine actualmente si existe o no habitualidad en el caso concreto de que se trate. La Jurisprudencia del TS, en algunas de sus sentencias, ha definido la habitualidad como la "condición del inculpado resultante de la persistencia o repetición de hechos de la misma índole o idéntica finalidad delictiva" ${ }^{\text {"1 }}$. Algunos afirman que "ha de ser habitual lo que se interpreta como maltrato en más de tres ocasiones" ${ }^{12}$; y que, desde luego no sirve el concepto

\footnotetext{
${ }^{58}$ Art. 161, párrafo 21 del Proyecto de Ley Orgánica del CP. de 1992.

${ }^{59}$ De este modo se expresa la Sentencia del Juzgado de Instrucción no 16 de Barcelona, de 5 de febrero de 1991: “(...) encontrándose en el interior del domicilio, hizo acto de presencia el marido, quien al tener conocimiento de la intención de la esposa, se opuso a ello, suscitándose una discusión entre ellos, en el transcurso de la cual él cogió a la esposa por los brazos y la zarandeó (...). En esas circunstancias la acción del marido se considera de lo que se podría llamar usual en la conducta de un ciudadano medio, y por tanto, exenta de responsabilidad criminal y procede absolver de las faltas que le imputan el Ministerio Fiscal y la Acusación particular"

${ }^{60}$ Un estudio clásico sobre abusos y malos tratos infantiles es CANTON DUARTE, J. y CORTES ARBOLEDA, M.R., Malos tratos y abuso sexual infantil, Siglo XXI de España Editores, Colección Psicología, Madrid, 1997.

${ }^{61}$ Véanse, entre otras, las sentencias del TS 7/2/61 y 24/3/77.

${ }^{62}$ GONZALEZ RUS, J.J., "Las lesiones", COBO DEL ROSAL, M. (dir.), Curso de Derecho Penal español, Parte especial, volumen I, Marcial Pons, Madrid, 1996, lección 4, p. 170.
} vol.08, nº. 03, Rio de Janeiro, 2015.pp. 1441-1480 
del art. $94^{63}$. Otros, por el contrario, introducen ligeros matices en su argumentación, lo que induce a cierta sospecha:

\begin{abstract}
El segundo elemento del tipo lo constituye la habitualidad, que aquí figura como concepto valorativo no afectado por la definición normativa contenida en el art. 94, cuyos efectos se limitan a lo previsto respecto a la suspensión y sustitución de las penas privativas de libertad, pese a que su contenido se corresponde con el criterio jurisprudencial dominante a propósito de los delitos "de hábito". Es por ello que, aun no siendo lo establecido en el art. 94 directamente aplicable, por expresa indicación legal, a este tipo de delito, representa el mejor criterio posible para garantizar una aplicación del mismo respetuosa con la garantía de la seguridad jurídica ${ }^{64}$.
\end{abstract}

Cierto es que todas estas precauciones para garantizar el principio de seguridad jurídica en la determinación del criterio de habitualidad, nos resultan un tanto sorprendentes teniendo en cuenta que las mujeres que deciden denunciar a sus compañeros agresores por delitos de malos tratos, llevan padeciendo violencias durante un período de 10 años. El propio médico forense del Juzgado de Zaragoza, D. Juan Antonio Cobo Plana, ya recogía en su célebre informe ${ }^{65}$ datos que podríamos calificar de escalofriantes. Sobre 250 casos de malos tratos que ha conocido en el desempeño de su cargo, la característica más frecuente en las mujeres que han sufrido agresiones habituales es su enorme tolerancia al maltrato. Y esto es así, puesto que el promedio de años de sufrimiento de violencia doméstica habitual oscilaba, ya por entonces, entre 10 años a 20 años.

Insistir en la aplicación dogmática del criterio de habitualidad significa ignorar la especificidad de este delito en el cual, la víctima, se ve obligada a convivir con el agresor y en donde, los bienes jurídicos amenazados y efectivamente lesionados, superan la integridad física. Nos referimos a la libertad o a la seguridad. En palabras del Tribunal Supremo de EE.UU., esto significaría condenar a la mujer maltratada a una muerte a plazos ${ }^{66}$. Y ello se confirma al toparnos con sentencias como la de 28 de marzo de 2000 de la Audiencia Provincial de Huelva cuya interpretación del criterio de habitualidad del antiguo art. 153 CP en su regulación anterior a junio de 1999,

\footnotetext{
${ }^{63}$ Artículo 94 del C.P., "A los efectos previstos en las Secciones 10 y 20 de este Capítulo se consideran reos habituales los que hubieren cometido tres o más delitos de los comprendidos en un mismo Capítulo, en un plazo superior a cinco años, y que hayan sido condenados por ellos".

${ }^{64}$ TAMARIT SUMALlA, J.M., "Las lesiones", en QUINTERO OliVARES, G. (dir.), VALLE MUÑIZ, J.M. (coord.), Comentarios al Nuevo Código Penal, Editorial Aranzadi, Pamplona, 1996, p. 725. El subrayado es mío. Véase también TAMARIT SUMALLA, J.M., "Artículo 153", en QUINTERO OLIVARES, G. (dir.), MORALES PRATS, F. (coord.), Comentarios al Nuevo Código Penal, 2a ed., Editorial Aranzadi, Pamplona, 2001. No obstante, es frecuente que la jurisprudencia exija, al menos, la acreditación de tres agresiones cercanas entre sí. Véanse, entre otras, la Sentencia de la Audiencia Provincial de Alicante de 3 de febrero de 2000, la Sentencia de la Audiencia Provincial de Guadalajara de 20 de marzo de 2002 y la Sentencia de la Audiencia Provincial de Sevilla de 30 de julio de 2003.

${ }^{65}$ COBO PLANA, J.A., Estudio médico forense de la violencia contra la mujer. Tesis doctoral. Facultad de Medicina de la Universidad de Zaragoza, 1990. Asimismo, véase CASTELLANO ARROYO, M., COBO PLANA, J.A., SÁNCHEZ BLANQUE, A. "Le profil des traits de personnalité des femmes victimes de violences", en Livre de Actes Xa Journées Mediterranéennes de Médecine Légale, 1992, Montpellier, 1992, pp. 331-335.

${ }^{66}$ BOYLE, C., "The Battered wife syndrome and selfdefence: Lavallee v.R.", en Women, Law and Social Change, Ed. por T. Brettel, 1993, p. 102.
} 
motiva la absolución del denunciado como responsable del delito de malos tratos habituales ${ }^{67}$. Textualmente: "El término habitualidad es equívoco e induce a confusión. Así se ha discutido si para esta habitualidad servía la condena anterior y parte de la doctrina ${ }^{68}$ lo rechaza a fin de evitar la doble incriminación, es decir, atentado al principio "non bis in idem".

En efecto, si se atiende a las faltas anteriores se suele decir que se vulneraría el principio que prohíbe la repetición de condenar por el mismo hecho, por tanto sólo podrán actuar las violencias físicas no denunciadas, que de repetirse, podrán dar lugar a un delito, "si es que no hubieran prescrito en el caso enjuiciado"69.

Afortunadamente, en el año 2000, dos sentencias del TS, contribuyen a despejar cualquier duda al respecto y a apostar por un criterio de habitualidad, no centrado propiamente en el número de actos de violencia y en la proximidad temporal de los mismos, cuanto en el clima de violencia contrastado que sufren la agredida y, en consecuencia, las personas vulnerables a su cargo. Nos referimos a las Sentencias del TS de 24 de junio de $2000^{70} \mathrm{y}$ a la de 7 de julio de $2000^{71}$, en donde el Alto Tribunal pone el acento en la actitud del agresor y en el ambiente de violencia en que viven los miembros de la familia, de tal modo que los actos de agresión no hacen sino exteriorizar dicha violencia. "En este caso, -y siguiendo el texto de la STTS de 7 de julio de 2000-, la sola lectura del relato histórico de la Sentencia pone de relieve que no estamos ante dos individuales acciones de agresión o violencia física surgidas aisladamente a lo largo del tiempo, sino ante dos agresiones que se manifiestan como la exteriorización singularizada de un estado de violencia permanente, ejercida por el acusado sobre su pareja, que permite su consideración como 'habitual'”. Según esta argumentación, dos actos de maltrato físico podrían ser suficientes para apreciar "habitualidad" en la violencia doméstica, ya que:

La más moderna línea interpretativa prescindiendo del automatismo numérico anterior, ha entendido con mayor acierto que lo relevante para apreciar la habitualidad, más que la pluralidad en sí misma, es la repetición o frecuencia que suponga una permanencia en el trato violento, siendo lo importante que el Tribunal llegue a la convicción de que la víctima vive en un estado de agresión permanente. En esta permanencia radica el mayor

\footnotetext{
${ }^{67}$ En este mismo sentido se ha pronunciado la Sentencia de la Audiencia Provincial de Gerona, de 5 de junio de 1998.

${ }^{68}$ En este sentido DOLZ LAGO entiende que el art. 153 "supone una violación patente del principio non bis in idem, al admitir que se tenga en cuenta en la valoración de la habitualidad hechos ya enjuiciados, incluso, tal vez, con sentencia absolutoria, hechos ya prescritos, o meras sospechas". Vid. DOLZ LAGO, M.J., "Violencia doméstica habitual: mitos y realidades", LL, 2000-3, pp. 1785. Al respecto, MARÍN DE ESPINOSA CEBALLOS propone modificar el art. 153 y explicitar que no se tendrá en cuenta los actos violentos que ya hubieren sido objeto de condena anteriormente para apreciar la habitualidad. Vid. MARÍN DE ESPINOSA CEBALlOS, E.B., HAMDORF, K., "El elemento de habitualidad en el delito de malos tratos del Código Penal sueco", CPC, nº 71, 2000, p. 430.

${ }^{69}$ Vid. Sentencia de la Audiencia Provincial de Huelva de 28 de marzo de 2000. Hemos de indicar que, pese a absolverlo como autor de un delito de malos tratos habituales, se condenó al acusado a tres años de prisión como autor de un delito de lesiones del art. $150 \mathrm{CP}$., a cuatro fines de semana de arresto como responsable de una falta de maltrato del art. 617.2 CP, a la pena de veinte días de multa con una cuota diaria de 200 pts. como autor de una falta de amenazas del art. 602.2 CP, prohibición de acercamiento durante cinco años, y en concepto de indemnización de daños y perjuicios el abono a la Sra. M. de 500.000 pts., pago de las costas incluidas las de la acusación particular. Esta Sentencia ha sido recurrida en casación ante el Tribunal Supremo.

${ }^{70}$ Sentencia del TS de 24 de junio de 2000.

${ }^{71}$ Sentencia del TS de 7 de julio de 2000.
} 
desvalor que la que resultaría de la mera agregación de las desvalorizaciones propias de cada acción individual.

Posteriormente, la línea jurisprudencial seguida confirma este paso importante en lo que a la interpretación de la habitualidad se refiere, revisando un criterio o categoría dogmática a todas luces discriminatoria. Este es el caso de la STS de 13 de abril de $2006^{72}$ (no 409/2006) o la de 23 de mayo de $2006^{73}$. Recientemente, tal y como se manifiesta el Alto Tribunal en STTS de 18 de julio de 2011:

La habitualidad no debe interpretarse en un sentido jurídico de multirreincidencia en falta de malos tratos -lo que podría constituir un problema de "non bis in idem"- parece más acertado optar por un criterio naturalístico entendiendo por habitualidad la repetición de actos de idéntico contenido, pero no siendo estrictamente la pluralidad la que convierte a la falta en delito, sino la relación entre autor y víctima más la frecuencia que ello ocurre, esto es la permanencia del trato violento, de lo que se deduce la necesidad de considerarlo como delito autónomo.

No podemos olvidar que la violencia padecida por las mujeres no sólo les afecta a ellas, sino a los miembros que conforman el núcleo familiar:

$\mathrm{Al}$ respecto hay que tener en cuenta lo que esa norma penal nos dice al final de su párrafo segundo, con lo que se pretende dar la máxima amplitud a este tercer elemento del tipo delictivo, cuando nos dice que tal habitualidad puede expresarse "con independencia de que dicha violencia se haya ejercido sobre la misma o diferentes víctimas de las comprendidas en ese artículo ( ...).

Asimismo, la jurisprudencia calificada de "menor", también ha aportado contribuciones interesantes en lo que al criterio de habitualidad se refiere. Destaquemos una importante sentencia, por pionera, -Sentencia de 26 de noviembre de 1999 del Juzgado de lo Penal no 1 de Sevilla- donde no sólo se realiza un análisis exhaustivo de la violencia contra las mujeres y sus causas, sino que aporta un claro posicionamiento antiformalista respecto del concepto de habitualidad del antiguo art. $153 \mathrm{CP}^{74}$ (también válido para el actual art. 173.2 CP). Dice así:

El bien jurídico protegido es la dignidad de la persona humana en el seno de la familia, $y$ concretamente su derecho a no ser sometida a trato inhumano o degradante alguno... El concepto de habitual al que alude el precepto no ha de entenderse en un sentido jurídico formal... sino en un sentido naturalístico, como un dato fáctico, ayuno de requisitos formales, o al menos desde una perspectiva criminológica-social... No siendo estrictamente la pluralidad la que convierte la falta en delito, sino la relación entre el autor y la víctima más la frecuencia con que ello ocurre, esto es la permanencia en el

\footnotetext{
72 “(n)o se trata, por ello, de una falta de lesiones elevada a delito por la repetición, ya que no puede especularse en torno a si son tres o más de tres las ocasiones en las que se ha producido la violencia. La habitualidad debe entenderse como concepto criminológicosocial, no como concepto jurídico formal por lo que será una conducta habitual la del que actúa repetidamente en la misma dirección con o sin condenas previas ya que éstas actuarían como prueba de la habitualidad”.

73 "(l)a reiteración de conductas de violencia física y psíquica por parte de un miembro de la familia, unido por los vínculos que se describen en el precepto ( ... vienen a crear, por su repetición, una atmósfera de vulneración de los deberes especiales de respeto entre las personas unidas por tales vínculos y por la nefasta incidencia en el desarrollo de los menores que están formándose y creciendo en ese ambiente familiar". Argumento también recogido en Sentencia de la Audiencia Provincial de Almería de 7 de octubre de 2005.

${ }^{74}$ En este mismo sentido, y más recientemente, se ha pronunciado la Sentencia de la Audiencia Provincial de Madrid de 15 de enero de 2001.
} 
trato violento... Lo importante es que el Juez llegue a la convicción de que la víctima vive en un estado de agresión permanente ${ }^{75}$.

Del mismo modo, la Sentencia de 1 de julio de 2002 del Juzgado de lo Penal no 3 de Granada entiende apoyándose en las Sentencias del TS de 24 de junio de 2000 y de 7 de julio de 2000- que hubo habitualidad en los hechos enjuiciados, "hechos que revelan, sin género alguno de dudas, un dilatado clima de convivencia enrarecida, clima generado por continuos episodios de violencia a lo largo de los años por parte del acusado y que el mismo ha decidido mantener con posterioridad al cese de la convivencia conyugal"76.

En este sentido, ya el Informe del CGPJ, de 7 de febrero de 2001 proponía prescindir de la exigencia de habitualidad y castigar aquellas agresiones acaecidas en el hogar que "alcancen la entidad suficiente para provocar la lesión o puesta en grave riesgo de los bienes jurídicos protegidos en este tipo de infracciones”.

Probablemente la valoración conjunta de la actitud del agresor, y del ambiente de violencia en que viven los distintos miembros de la familia -y que sufren individualmente actos violencia física y psíquica-, "nos lleve a considerar la existencia de una infracción que se alimenta de hechos no atípicos sino punibles como falta y por ello se trata en realidad de una especial figura de falta que por ser continuada asciende a la condición de delito"77. Como afirma Antonio del Moral - palabras recogidas por la Sentencia no 144/01 del Juzgado de lo Penal no 11 de Sevilla, de 3 de abril de 2001-:

La reiteración de actividades de violencia, hasta crear una atmósfera irrespirable o un clima de sistemático maltrato, se castiga no por lo que comporta de ataque a la incolumidad física, sino por lo que tiene de violación de deberes especiales de respeto al cónyuge y a los hijos y familiares; por lo que supone de afectación del sentimiento de seguridad; por la nefasta incidencia en el desarrollo de los menores que están formándose y creciendo en ese ambiente familiar: Se trata de valores constitucionales que giran en torno a la necesidad de protección a la familia $^{78}$.

\footnotetext{
${ }^{75}$ Vid. Sentencia del Juzgado de lo Penal no 1 de Sevilla, de 26 de noviembre de 1999. En este mismo sentido, merece la pena destacar la posición de Sentencia de la Audiencia Provincial de Sevilla de 31 de julio de 2003 quien "para apreciar la habitualidad, más que la pluralidad en sí misma, (entiende que) es la repetición o frecuencia que suponga una permanencia en el trato violento, siendo lo importante que el Tribunal llegue a la convicción de que la víctima viven en un estado de agresión permanente”.

${ }^{76}$ Vid. Sentencia del Juzgado de lo Penal no 3 de Granada, de 1 de julio de 2002. Posteriormente, la condena por un delito de lesiones por violencia habitual familiar fue revocada, ratificando únicamente la condena por falta de lesiones, según Sentencia $\mathrm{n}^{\circ}$ 643/2002, de la Audiencia Provincial de Granada, Sección 2a, de 11 de noviembre de 2002. No se hace mención alguna a la habitualidad. Las razones de esta estimación parcial de la condena: el cambio de testimonio de la hija -probablemente por presiones psicológicas del padre-agresor-, y la no declaración de la agredida en este nuevo proceso.

${ }_{77}$ Dice así la Sentencia de 30 de septiembre de 1999 del Juzgado de lo Penal de no 7 de Sevilla confirmada posteriormente en apelación, por la Sección 3a de la Audiencia Provincial de Sevilla el 6 de abril de 2000: "Dicho precepto (art. 153 CP) obedece, al igual que el anterior 425 del CP., a la deficiente protección de los miembros físicamente más débiles del grupo familiar frente a conductas sistemáticamente agresivas de otros miembros del mismo, se tipifican como delitos de malos tratos ejercidos sobre el cónyuge o pareja de hecho cuando, a pesar de no integrar individualmente considerados más que una sucesión de faltas, se producen de modo habitual encontrándonos ante una infracción que se alimenta de hechos no atípicos sino punibles como falta, y por ello se trata en realidad de una especial figura de falta que por ser continuada asciende a la condición de delito".

${ }^{78}$ Sentencia no 144/01 del Juzgado de lo Penal no 11 de Sevilla, de 3 de abril de 2001. En este mismo sentido se ha pronunciado la STTS de 7 de septiembre de 2000.
} 
No obstante, algunos asuntos de suma proyección mediática giran en torno a este particular. Nos referimos al reciente pronunciamiento del TS de 4 de mayo de 2015 que devuelve la exposición razonada al Juzgado de Violencia sobre la Mujer no 2 de las Palmas de Gran Canaria y acuerda, en torno a la investigación del exministro López Aguilar sobre Violencia de Género a su excónyuge, que "por el momento" no ha lugar a la apertura del procedimiento penal del eurodiputado, en tanto que las diligencias (iniciadas por su hijastro, don Gorka de la Nuez, el 10 de enero de 2015, que no fueron ni recurridas por el fiscal ni por la perjudicada) fueron archivadas de forma definitiva en un auto que ya es firme. Esa firmeza le otorga, según el TS, el valor de cosa juzgada y equivale a una sentencia absolutoria. Aunque posteriormente hubo un segundo procedimiento, abierto por la Policía para aclarar dos incendios de la casa de la ex mujer, con declaración de la agredida, el problema que ve el Supremo es que "la lectura de la declaración judicial prestada por Doña Natalia ante la jueza de violencia sobre la Mujer" revela que "no existe una sucesión ordenada de los hechos delictivos atribuidos al aforado". En ocasiones, la referencia es a actos sucedidos al día anterior y en otros casos, años antes o en fechas indeterminadas. Es decir, que una parte de la declaración tampoco podría usarse a afectar a períodos anteriores a la primera denuncia archivada. Finalmente el TS concluye, dejando claro el problema que planteamos que:

Resulta ineludible que la jueza instructora precise en su exposición razonada qué hechos podrían dar lugar, si así lo considera acreditado, a la imputación del aforado y que excluya aquellos otros sobre los que se proyecte la resolución del sobreseimiento libre acordada tras la denuncia inicial de don Gorka de la Nuez.

\section{LA EXIGENCIA JUDICIAL DEL ÁNIMO SUBJETIVO DE DOMINACIÓN}

Últimamente se viene discutiendo por la doctrina judicial la necesidad de un ánimo subjetivo constatado de dominación ${ }^{79}$ para poder aplicar el art. 153.1 CP. La lectura del mismo, en ningún caso alude a este animus o intención dominadora, sin embargo existe ya jurisprudencia que lo exige como es el caso de la Audiencia Provincial de Murcia (Sección 3a). Este requisito inventado -que no legal- obliga a blindar los fallos judiciales de los Tribunales menores con el objetivo de no ser recurridos por este particular ante la Audiencia Provincial, lo que viene a casi extrapolar - de manera encubierta- las dificultades ya señaladas al analizar el criterio de "la habitualidad" exigida por el art. 173.2. CP.

Un ejemplo de ello podemos encontrarlo en la Sentencia del Juzgado de lo Penal $n^{\circ} 1$ de Cartagena, $n^{\circ}$ 26/2013, de 18 de febrero, que consciente de este requerimiento extralegem, se pronuncia de este modo:

\footnotetext{
${ }^{79}$ En tanto que el artículo 1.1 de la L.O.1/2004, de 28 de diciembre, de medidas de protección integral contra la Violencia de Género concreta que el objeto de la Ley es "actuar contra la violencia que, como manifestación de la discriminación, la situación de desigualdad y las relaciones de poder de los hombres sobres las mujeres, se ejerce sobre éstas por parte de quienes sean o hayan sido sus cónyuges o de quienes estén o hayan estados ligados a ellas por relaciones similares de afectividad, aun sin convivencia”.
} vol.08, no.03, Rio de Janeiro, 2015.pp. 1441-1480 1472 
Finalmente se ha discutido la existencia de un ánimo subjetivo de dominación. Esta juzgadora en numerosas sentencias ha defendido que no es necesario la concurrencia de tal ánimo subjetivo de dominación, sin embargo es cierto que existe jurisprudencia que así lo exige, entre otras la Sección $3^{a}$ de la Audiencia Provincial de Murcia. Pues bien, en este caso entiende esta juzgadora que concurre dicho ánimo puesto que la conducta del acusado en la noche del 29-6-12 responde a una manifestación de dominación y sometimiento y es que ha quedado acreditado que el acusado acudió al bar "Q caña" porque sabía que estaba el chico con el que había comenzado a salir la denunciante, de modo que el acusado quiso que ella bajara del coche para ver su reacción quien se negó a bajar, lo que corroboró en el acusado que era cierto que la denunciante tenía algo con ese chico, razón por la que no aceptando esa relación, le golpeó en la cara y después por diversas partes del cuerpo. Resulta evidente que la actitud del acusado responde a una clara manifestación de sometimiento, dominación y desigualdad derivada del hecho de no aceptar que Carlota hubiera comenzado otra relación. Pero es que además tanto la denunciante como varios testigos declaran que el acusado controlaba a Carlota. Así por ejemplo, la denunciante manifiesta que el acusado la tenía controlada, y que se avergonzaba de ella porque no tenía estudios y porque tenía un hijo; la encargada de la tienda donde Carlota trabajaba manifiesta que la "tenía súper controlada y era muy posesivo" "que le decía "hazte una coleta, mira qué pelo llevas, y que ella se cambiaba de ropa para verle. Y sus hermanas afirman que era muy controlador. Pues bien, tales declaraciones vienen corroboradas por varios emails, obrantes en los folios 331 y 349 . En el folio 331, el acusado le dice a Carlota "en mi casa a las 14:15 pero con falda larga", en otro le dice "o sea bebiste y con minifalda", en otro emails ella le dice "estoy bastante preocupada porque no sé si voy demasiado hortera o te gusta mi estilismo", y en el folio 349 le dice "ya me he dejado las patillas, tú córtate el pelo.

Existen otras dificultades halladas en el tratamiento judicial de los malos tratos habituales, que no podemos abordar en este momento ${ }^{80}$, pero que sí deben ser cuanto menos mencionadas. Nos referimos a la preocupante inclinación a aplicar circunstancias atenuantes y eximentes de la responsabilidad criminal del agresor como el consumo de alcohol, la celotipia, el desamor e incluso la confesión a las autoridades. Justificaciones sociales que persiguen el control de la mujer en atención a la fragilitas sexus, pero que también ponen de manifiesto la verdadera debilidad y dependencia de quien ejerce ese control. "Es por eso que son una buena excusa para el hombre, una explicación suficiente para la mujer, una adecuada justificación para la sociedad y una atenuante o eximente lícita para la Justicia” ${ }^{81}$. Sin embargo, el rechazo del alegato de legítima defensa para episodios de autoprotección femenina, y la tendencia a aplicar "el trastorno mental transitorio" como único escape de las “mujeres agredidas que se defienden” de las garras del Derecho Penal perpetra otra violencia del Derecho. Las mujeres tienen que aceptar su trastorno y admitir su patología individual. Sin duda, el Derecho y la Ciencia jurídica son masculinas y adjudican género.

\footnotetext{
${ }^{80} \mathrm{Al}$ respecto, consúltese GIL RUZ, J.M., Los diferentes rostros de la Violencia de Género, Dykinson, Madrid, 2007.

${ }^{81}$ LORENTE ACOSTA, M., Mi marido me pega lo normal. Agresión a la mujer: realidades y mitos, opus cit, p. 73. vol.08, n. 03, Rio de Janeiro, 2015.pp. 1441-1480
} 


\section{A MODO DE CONCLUSIÓN}

Sirva este análisis teórico-práctico para reflexionar si ciertamente, los derechos constitucionales como la vida, la integridad, la libertad, la seguridad, y la dignidad de las mujeres en tanto que ciudadanas se encuentran realmente tutelados por nuestro Ordenamiento Jurídico y garantizados por los Poderes Públicos; o si por el contrario, se encuentran abandonados o, mejor dicho, aforados a otra jurisdicción, la doméstica extra-jurídica, representada por el varón, cabeza de familia quien cuida de que se observe su legislación autónoma. Romper con el silencio, apelar a la intervención estatal, reclamar una mayor sensibilidad de la Justicia, modificar las categorías científico-jurídicas ya desfasadas y gritar que el terrorismo doméstico no es más que un extremo de la violencia estructural de género, serviría para evitar que la privatización de la violencia volviera a planear sobre la ciudadanía. No olvidemos que la violencia de género explícitamente rechazada e implícitamente tolerada sigue siendo un mecanismo válido para mantener a las mujeres en una posición de subordinación, erigiendo la diferencia entre hombres y mujeres en eterna desigualdad.

Sólo un aspecto más que merece nuestra atención como juristas antes de concluir este capítulo: el peligro de disolución de la Violencia de Género nuevamente en Violencia doméstica o familiar en la inminente reforma del Código Penal. La gravedad de dicha propuesta apuntada por algunas voces políticas supondría: la desactivación del componente desestructurador del moderno Derecho antidiscriminatorio, un paso atrás de gigante en la lucha por la erradicación de la discriminación estructural ciudadana, y desde luego un incumplimiento del Derecho Internaciona ${ }^{82}$ y Europeo ratificado por España ${ }^{83}$ ante el que deberemos, mucho me temo, algo más que explicaciones ${ }^{84}$.

\footnotetext{
${ }^{82}$ No pretendo hacer una relación de Convenios y Tratados firmados por España sobre este particular. De cualquier modo no pueden desconocerse las obligaciones adquiridas a nivel internacional en la CEDAW (1979) y ratificadas en 1984, Beijing (1995), ni europeas (Tratado de Ámsterdam y Tratado de Lisboa), entre otras.

${ }^{83}$ A nivel europeo, recientemente, el 18 de marzo de 2014, Espana ha ratificado el Convenio del Consejo de Europa sobre prevención y lucha contra la violencia contra la mujer y la violencia doméstica (Convenio de Estambul), abierto a la firma en Estambul el 11 de mayo de 2011 y que entró en vigor el 1 de agosto de 2014. Se trata del primer instrumento jurídico vinculante europeo, que conmina a los Estados a responder de manera efectiva contra la violencia de género y los responsabiliza de las dejaciones o incumplimientos de sus compromisos. Al respecto, véase GIL RUIZ, J.M., "España ante el Convenio de Estambul y la Crisis del Estado de Bienestar: cuestión de principio(s) y de responsabilidad institucional", Revue de droit de l'homme, Paris Ouest-Nanterre, 2015 (en prensa).

${ }^{84}$ La ratificación de la Convención para la Eliminación de toda forma de Discriminación contra la Mujer, adoptada en 1979, y ratificada por 187 países, entre ellos España en 1984, compromete a nuestro país a crear y desarrollar políticas encaminadas a eliminar cualquier atisbo de discriminación contra las mujeres tomando las medidas necesarias a todos los niveles del Estado. Entre las obligaciones del Estado figuran la de informar sobre la aplicación de los artículos de la Convención mediante un informe cuatrienal que ha de ser presentado ante el Comité de la CEDAW, el mismo organismo, recordemos, que emitió el pasado julio de 2014, la histórica condena a España por no haber protegido a una víctima de violencia de género, ni a su hija, en un caso que terminó con el asesinato de la menor.
} 


\title{
THE WOMAN OF LEGAL DISCOURSE: A CONTRIBUTION FROM THE CRITICAL LEGAL THEORY
}

\begin{abstract}
Recover the work of Carole Pateman The Woman of legal discourse allows repair in the three phases identified by her around the feminist critique of law. Connect these three periods-the Law is sexist, Law is male and the law is gender-priority within a framework of analysis such as gender violence in the context of couple, can detect not only urges reflection and evaluation legislative commitment adopted by the Spanish State, but also and especially, review and falsification of scientific-legal categories and seized learned from the Academy and applied automatically in judgments. This scientific anachronism, only adds more violence (secondary victimization) women finally decide to report. Finally, the shielding of the concept of gender violence, linking citizens and the State, stands as essential to the imminent threat of legal dissolution of the latter in the domestic or family violence that brings us back to the unfailing and dangerously vulnerable victim.
\end{abstract}

Keywords: Gender Violence, Citizenship, diligence State, juridical science

\section{REFERENCIAS BIBLIOGRÁFICAS}

AÑÓN, M.J, ¿Igualdad ma non troppo? Una reflexión crítica sobre la reciente legislación española en materia de igualdad entre mujeres y hombres, en Sociología del Diritto, Franco Angeli Edizioni, vol. 34, Italia, 2008.

AÑÓN, M.J. y MESTRE i MESTRE, R, Violencia contra las mujeres: discriminación, subordinación y Derecho, en BOIX, J. y MARTÍNEZ, E. (coord.), La nueva Ley contra la Violencia de género, Madrid, Iustel, 2005, pp. 31 63.

ASOCIACIÓN DE MUJERES JURISTAS THEMIS, Respuesta penal a la violencia familiar, Consejo de la Mujer de la Comunidad de Madrid, 1999.

BECH, L., Los adolescentes no perciben la violencia como tal, en Blasting News, Sociedad, 19 de mayo de 2015.

BIRGIN, H. \& GHERARDI, N., (Coords.), Reflexiones Jurídicas desde la Perspectiva de Género, Editorial Fontamara, México D.F., 2011.

BODELÓN, E., (Coord.), Violencia de Género y las respuestas de los sistemas penales, Ed. Didot, Buenos Aires, 2012.

BOYLE, C., The Battered wife syndrome and selfdefence: Lavallee v.R, en Women, Law and Social Change, Ed. por T. Brettel, 1993.

CANTON DUARTE, J. y CORTES ARBOLEDA, M.R, Malos tratos y abuso sexual infantil, Siglo XXI de España Editores, Colección Psicología, Madrid, 1997. 
CÁRDENAS, M., CARCIA, L,; Límits i possibilitats de la coordinació informal els circuits locals contra la violencia de gènere, Comunicación al II Congreso Catalán de gestión pública, julio de 2006. Disponible en internet en el link: http://www20.gencat.cat/portal/site/eapc/memuitem.ca54cfbb17b4abf5272a63a7b0c0ela0.

CASTELLANO ARROYO, M., COBO PLANA, J.A., SÁNCHEZ BLANQUE, A., Le profil des traits de personnalité des femmes victimes de violences, en Livre de Actes Xa Journées Mediterranéennes de Médecine Légale, 1992, Montpellier, 1992, pp. 331-335.

CGPJ, Informe del Grupo de Experto/as en violencia de género y doméstica del CGPJ acerca de los problemas técnicos detectados en la aplicación de la L.O.1/2004, CGPJ, Madrid, 2011.

CGPJ, Datos de denuncias, procedimientos penales y civiles registrados, órdenes de protección solicitadas en los juzgados de violencia sobre la mujer (JVM) y sentencias dictadas por los órganos jurisdiccionales en esa materia en el año 2011, CGPJ, Madrid, 2011.

COBO PLANA, J.A., Estudio médico forense de la violencia contra la mujer. Tesis doctoral. Facultad de Medicina de la Universidad de Zaragoza, 1990.

CUBELLS, J., CALSAMIGLIA, A., ALBERTÍN, P., El ejercicio profesional en el abordaje de la violencia de género en el ámbito jurídico-penal: un análisis psicosocial, en Anales de psicología, 2010, vol. 26, nº 1, pp. 369-377.

DI CORLETO, J., La construcción legal de la violencia contra las mujeres, en DI CORLETO, J., (comp.), Justicia, género y violencia, Libraria, Buenos Aires, 2010, pp. 9-22.

(comp.), Justicia, género y violencia, Libraria, Buenos Aires, 2010

DOLZ LAGO, M.J., Violencia doméstica habitual: mitos y realidades, LL, 2000-3, pp. 1785.

EISENSTEIN, A., The female body and the law, Berkeley, University of California Press, 1988.

FACIO, A., Metodología para el análisis de género del fenómeno legal, en FACIO, A. y FRÍES, L. (coord.), Género y derecho, Santiago de Chile, LOM/La Morada, 1999, pp. 99-136.

FACIO, A. y FRÍES, L. (Coord.), Género y derecho, Santiago de Chile, LOM/La Morada, 1999.

FREIXES SANJUÁN, T., Las normas de prevención de la violencia de género. Reflexiones en torno al marco internacional y europeo, Artículo 14. Una perspectiva de género, Instituto Andaluz de la Mujer, no 6, 2001, pp. 420.

GIL RUIZ, J.M., Las nuevas Técnicas Legislativas en España, Tirant Lo Blanch, Valencia, 2012. Los diferentes rostros de la Violencia de Género, Dykinson, Madrid, 2007.

España ante el Convenio de Estambul y la Crisis del Estado de Bienestar: cuestión de principio(s) y de responsabilidad institucional, Revue de droit de l' homme, Paris Ouest-Nanterre, 2015 (en prensa). pp. $9-158$.

(ed.), Violencia Institucional de Género, Revista Anales de la Cátedra Francisco Suárez, Granada, 2013, 
GONZALEZ RUS, J.J., Las lesiones, COBO DEL ROSAL, M. (dir.), Curso de Derecho Penal español, Parte especial, volumen I, Marcial Pons, Madrid, 1996, lección 4.

HEIM, D., Acceso a la Justicia y violencia de género, Anales de la Cátedra Francisco Suárez, no 48, Granada, 2014, pp. 107-130.

LAGARDE, M., Sinergia por nuestros derechos humanos. Ante la violencia contra las mujeres en España, Guatemala y México, en LAGARDE, M. y VALCÁRCEL, A., (Coord.), Feminismo, género e igualdad, Madrid, Agencia Española de la Cooperación Internacional para el desarrollo, Fundación Carolina, 2011, pp. 63-83.

LAGARDE, M. y VALCÁRCEL, A., (Coord.), Feminismo, género e igualdad, Madrid, Agencia Española de la Cooperación Internacional para el desarrollo, Fundación Carolina, 2011.

LARRAURI, E., Violencia doméstica y legítima defensa -un caso de aplicación masculina del Derecho-, en LARRAURI, E. y VARONA, D., Violencia doméstica y legítima defensa, E.U.B., Barcelona, 1995.

Desigualdades sonoras, silenciosas y olvidadas: género y derecho penal, Anuario de la Facultad de Derecho de la UAM, Madrid, 2009.

Violencia de género en España: Tres años después de la L.O. 1/2004, de 28 de diciembre de Medidas de Protección Integral contra la Violencia de Género, en BIRGIN, H. \& GHERARDI, N., (coords.), Reflexiones Jurídicas desde la Perspectiva de Género, Editorial Fontamara, México D.F., 2011.

(ed.), Mujeres, Derecho Penal y Criminología, Siglo XXI de España Editores, 1994.

LARRAURI, E. y VARONA, D., Violencia doméstica y legítima defensa, E.U.B., Barcelona, 1995.

LAURENZO, P., La violencia de género en el Derecho Penal: un paternalismo punitivo, en LAURENZO, P, MAQUEDA, M.L., RUBIO, A. (ed.), Género, violencia y Derecho, Tirant lo Blanch, Valencia, 2008, pp. 329-362.

LAURENZO, P, MAQUEDA, M.L., RUBIO, A. (ed.), Género, violencia y Derecho, Tirant lo Blanch, Valencia, 2008 .

LOURIDO, M., en http://cadenaser.com/ser(2015, 02/16/sociedad.

MARÍN DE ESPINOSA CEBALLOS, E.B., HAMDORF, K., El elemento de habitualidad en el delito de malos tratos del Código Penal sueco, CPC, nº 71, 2000.

PATEMAN, C., La mujer del discurso jurídico, en LARRAURI PIJOÁN, E. (ed.), Mujeres, Derecho Penal y Criminología, Siglo XXI de España Editores, 1994. Traducción de Elisabeth Almeda.

PITCH, T., Un Derecho para dos. La construcción jurídica de género, sexo y sexualidad, Editorial Trotta, Madrid, 2003.

SCHNEIDER, E., Mujeres maltratadas y la elaboración de leyes feministas: definición, identificación y desarrollo de estrategias, en DI CORLETO, J., (Comp.), Justicia, género y violencia, Libraria, Buenos, Aires, 2010, pp. 23-42.

SCHMAL, N., CAMPS, P., Repensando la relación entre la ley y la violencia hacia las mujeres: una aproximación a los discursos de los/las agentes del ámbito judicial en relación a la ley integral de violencia de género en España, en Psicoperspectiva. Individuo y Sociedad, vol. 7, nº 1, 2008, pp. 33-58. 
STARK, E., FLITCRAFT, A. Y FRAZIER, W, Medicine and patriarcal violence: The social construction of a "private" event, International Journal of Health Service, 1979, 9, pp. 461-493.

TAMARIT SUMALLA, J.M., Las lesiones, en QUINTERO OLIVARES, G. (dir.), VALLE MUÑIZ, J.M. (coord.), Comentarios al Nuevo Código Penal, Editorial Aranzadi, Pamplona, 1996, p. 725. Artículo 153, en QUINTERO OLIVARES, G. (dir.), MORALES PRATS, F. (coord.), Comentarios al Nuevo Código Penal, 2a ed., Editorial Aranzadi, Pamplona, 2001.

\section{Referencias Jurisprudenciales}

Jurisprudencia del TS

Sentencia del TS de 22 de febrero de 1991, RJ 1991/1349.

Sentencia del TS de 14 de junio de 1991, RJ 1991/4718.

Sentencia del TS de 18 de octubre de 1991, RJ 1991/7311.

Sentencia del TS de 20 de abril de 1992, RJ 1992/3165.

Sentencia del TS de 28 de mayo de 1992, RJ 1992/4396.

Sentencia del TS de 4 de junio de 1992, RJ 1992/5444.

Sentencia del TS de 22 de diciembre de 1992, RJ 1992/10465.

Sentencia del TS de 8 de marzo de 1993, RJ 1993/1992.

Sentencia del TS de 9 de marzo de 1993, RJ 1993/2163.

Sentencia del TS de 7 de mayo de 1993, RJ 1993/3860.

Sentencia del TS de 3 de octubre de 1994, RJ 1994/7604.

Sentencia del TS de 24 de junio de 2000.

Sentencia del TS de 7 de julio de 2000.

Sentencia del TS de 25 de julio de 2000.

Sentencia del TS de 25 de julio de 2000.

Sentencia del TS de 7 de septiembre de 2000.

Sentencia del TS de 9 de octubre de 2000.

Sentencia del TS 178/2001, de 13 de febrero. 
Sentencia del TS 1214/2003, de 24 de septiembre.

Sentencia del TS 949/2008, de 27 de noviembre.

Sentencia del TS 965/2008, de 26 de diciembre.

Sentencia del TS 25/2009, de 22 de enero.

Sentencia del TS 93/2009, de 29 de enero.

Sentencia del TS 282/2009, de 10 de febrero.

Sentencia del TS 854/2009, de 9 de julio.

Sentencia del TS 1180/2010, de 22 de diciembre.

\section{Jurispridencia Menor}

Sentencia del Juzgado de Instrucción no 16 de Barcelona, de 5 de febrero de 1991.

Sentencia del Juzgado de lo Penal de no 7 de Sevilla, de 30 de septiembre de 1999.

Sentencia del Juzgado de lo Penal no 1 de Sevilla, de 26 de noviembre de 1999.

Sentencia del Juzgado de 1ª Instancia e Instrucción de Loja, de 13 de abril de 2000.

Sentencia del Juzgado de lo Penal no 11 de Sevilla, de 3 de abril de 2001.

Sentencia del Juzgado de lo Penal no 8 de Málaga, de 17 de julio de 2000.

Sentencia del Juzgado de lo Penal no 3 de Granada, de 1 de julio de 2002.

Sentencia del Juzgado de Instrucción nº 3 de Roquetas de Mar, de 26 de septiembre de 2000.

Sentencia del Juzgado de lo Penal no 3 de Granada, de 1 de julio de 2002.

Sentencia de la Audiencia Provincial de Barcelona, de 31 de enero de 1997.

Sentencia de la Audiencia Provincial de Alicante, de 3 de febrero de 2000.

Sentencia de la Audiencia Provincial de Huelva, de 28 de marzo de 2000.

Sentencia de la Audiencia Provincial de Sevilla, de 6 de abril de 2000.

Sentencia de la Audiencia Provincial de Madrid, de 15 de enero de 2001.

Sentencia de la Audiencia Provincial de Jaén, Sección 2a de 18 de enero de 2002. 
Sentencia de la Audiencia Provincial de Guadalajara, de 20 de marzo de 2002.

Sentencia de la Audiencia Provincial de Granada, de 11 de noviembre de 2002.

Sentencia de la Audiencia Provincial de Sevilla, de 10 de enero de 2003.

Sentencia de la Audiencia Provincial de Gerona, de 31 de enero de 2003.

Sentencia de la Audiencia Provincial de Madrid, de 28 de febrero de 2003.

Sentencia de la Audiencia Provincial de Valladolid, de 11 de marzo de 2003.

Sentencia de la Audiencia Provincial de Alicante, de 20 de marzo de 2003.

Sentencia de la Audiencia Provincial de La Coruña, de 25 de marzo de 2003.

Sentencia de la Audiencia Provincial de Sevilla, de 30 de julio de 2003.

Sentencia de la Audiencia Provincial de Sevilla de 31 de julio de 2003.

Sentencia de la Audiencia Provincial de Almería, de 7 de octubre de 2005.

Sentencia de la Audiencia Provincial de Córdoba, de 16 de noviembre de 2011.

Trabalho enviado em 22 de fevereiro de 2015.

Aceito em 25 de maio de 2015. 